\title{
Macrophage imaging and subset analysis using single-cell RNA sequencing
}

\author{
Sean Arlauckas ${ }^{1}$, Nuri Oh${ }^{1}$, Ran Li1 ${ }^{1,2}$, Ralph Weissleder ${ }^{1,2,3}$, Miles A. Miller ${ }^{1,2}$ \\ 1. Center for Systems Biology, Massachusetts General Hospital Research Institute, Boston, MA 02114, USA \\ 2. Department of Radiology, Massachusetts General Hospital and Harvard Medical School, Boston, MA 02115, USA \\ 3. Department of Systems Biology, Harvard Medical School, Boston, MA 02115, USA \\ $\bowtie$ Corresponding author: miles.miller@mgh.harvard.edu
}

(C) The author(s). This is an open access article distributed under the terms of the Creative Commons Attribution License (https://creativecommons.org/licenses/by/4.0/). See http://ivyspring.com/terms for full terms and conditions.

Received: 2020.07.01; Accepted: 2020.10.19; Published: 2021.01.01

\begin{abstract}
Macrophages have been associated with drug response and resistance in diverse settings, thus raising the possibility of using macrophage imaging as a companion diagnostic to inform personalized patient treatment strategies. Nanoparticle-based contrast agents are especially promising because they efficiently deliver fluorescent, magnetic, and/or radionuclide labels by leveraging the intrinsic capacity of macrophages to accumulate nanomaterials in their role as professional phagocytes. Unfortunately, current clinical imaging modalities are limited in their ability to quantify broad molecular programs that may explain (a) which particular cell subsets a given imaging agent is actually labeling, and (b) what mechanistic role those cells play in promoting drug response or resistance. Highly multiplexed single-cell approaches including single-cell RNA sequencing (scRNAseq) have emerged as resources to help answer these questions. In this review, we query recently published scRNAseq datasets to support companion macrophage imaging, with particular focus on using dextran-based nanoparticles to predict the action of anti-cancer nanotherapies and monoclonal antibodies.
\end{abstract}

\section{Introduction}

Non-invasive quantification of macrophages $(\mathrm{M} \Phi)$ by imaging has shown potential in applications where their heterogeneous behaviors contribute to disease progression and drug responses, including in infection, inflammation, and cancer. $M \Phi$ can be among the most abundant cell-types in local diseased tissues and can affect drug action through direct drug engagement and indirectly by altering multicellular signaling within tissue. Drug classes including biologics and nanomaterials are especially influenced by $M \Phi$, which interact through $M \Phi$-expressed complement, lipid, scavenger, and Fc receptors. MФ also influence pharmacology without binding or transporting drugs directly, for instance through shaping vascular function and inflammatory signaling. These cells contribute to wound healing, angiogenesis, fibrosis, blood-brain-barrier function, and coagulation processes that broadly govern drug transport [1].

Therapeutics continue to be developed that target or are influenced by MФ [2], and many of these agents exhibit high patient-to-patient variability in both safety and efficacy. This variability is particularly acute in the treatment of solid cancers. As one example, the liposomal irinotecan nanotherapy (marketed as Onivyde for the treatment of metastatic pancreatic adenocarcinoma) [3] has been developed in principle to deliver toxic chemotherapy payloads more selectively and safely to tumors via passive "enhanced permeability and retention" (EPR) effects $[4,5]$. While evidence for EPR effects are strong in some patients with highly vascularized tumors marked by dysfunctional lymphatics and phagocyte infiltration, in other cases tumors are fibrotic, poorly vascularized, contain high interstitial fluid pressure, and consequently exhibit low EPR effects and low 
nanotherapy accumulation [6]. In mice, the EPR effect can be dependent on tumor associated MФ (TAM) accumulation $[7,8]$, and in patients $M \Phi$ imaging positively correlates with initial nanotherapy response [9]. Past clinical trials, including one that studied a small cohort of melanoma patients, have found correlation between $M \Phi$ infiltration and poor response to immune checkpoint blockade using the programmed death 1 (PD1) targeted monoclonal antibody $(\mathrm{mAb})$ nivolumab [10]. Additionally, in a small study of 9 patients with melanoma, kinase inhibitor response correlated more negatively with the drug-induced accumulation of $\mathrm{M} \Phi$ than any other immune cell-type assessed [11]. These instances of clinical correlations and many others suggest that $\mathrm{M} \Phi$ quantification may be useful in predicting responses to a variety of different drugs [12].

The ability of phagocytes including $М \Phi$ to efficiently accumulate nanoparticles has been leveraged for quantitative $M \Phi$-selective imaging in cancer, inflammation, and infectious diseases [13-18]. The carboxymethyl dextran coated iron oxide nanoparticle ferumoxytol (Feraheme) is one example of a clinical agent used to image $\mathrm{M} \Phi$ in patients. Ferumoxytol is approved by the U.S. Food and Drug Administration (FDA) for the treatment of iron deficiency anemia in patients with chronic kidney disease, and is used on an investigational basis to image $M \Phi$ by magnetic resonance imaging (MRI) [9, 19-22]. Other examples include the crosslinked polyglucose nanoparticle Macrin, which shares similar size $(\sim 20 \mathrm{~nm})$ and carboxymethyl dextran components as ferumoxytol, but which can be imaged by ${ }^{64} \mathrm{Cu}$ positron emission tomography / X-ray computed tomography (PET/CT), for instance to visualize disseminated metastatic lung cancer [15]. Numerous other promising $\mathrm{M} \Phi$ imaging agents have been described and are extensively reviewed elsewhere [22-26].

Clinical imaging modalities are unfortunately limited in their ability to simultaneously measure large panels of molecular markers. One advantage of imaging general cell-types such as $M \Phi$ is that they participate in disease processes through multiple molecular pathways, and thus may apply to diverse applications. It is clear that multiple overlapping molecular pathways may contribute to a given disease or drug-response process, and $\mathrm{M} \Phi$ quantification may better capture a composite description of these pathways compared to individual measurement of a single molecular feature. The corresponding trade-off is loss in detailed molecular information that can translate into mechanistic understanding. Even "targeted" nanoparticles and imaging agents inevitably accumulate at some level in off-target cell populations due to promiscuous target expression and complex cell-uptake pathways [27]. Therefore, a need arises to understand which cellular subsets are actually being imaged by a given probe, and what molecular pathways are operating to influence disease or drug-response processes. It is encouraging that highly multiplexed single-cell analytical technologies, particularly single-cell RNA sequencing (scRNAseq), have emerged as naturally complementary approaches to address these knowledge gaps.

The commercialization of scRNAseq and other single-cell "-omic" methods, combined with large-scale consortium efforts such as the Human Cell Atlas Project to deploy them, has driven growth in the amount of publicly available data in useable formats. The scale of these datasets has increased over time, with $\sim 4,500$ cells representing a cutting edge dataset in 2016 [28], to 700,000 cells in 2020 [29], albeit at diminished sequencing depth per cell in the latter. These datasets can provide broad perspective into the cell subsets that express a receptor of interest, give insight into the molecular programs co-expressed in those cell types, and increasingly support incorporation of post-transcriptional regulation [30], functional genomics [31], spatial localization [32], and drug or probe uptake [33].

With respect to $M \Phi$ imaging, scRNAseq has been especially valuable in highlighting distinct $\mathrm{M} \Phi$ polarization states, patterns of multicellular communication, and pathways of $M \Phi$-influenced drug action within tissues [34-37]. МФ imaging and companion therapeutic applications can be categorized by the class of $\mathrm{M} \Phi$ receptors or pathways being targeted, and this manuscript is organized accordingly. The review focuses on key $\mathrm{M} \Phi$ receptor families and pathways of direct material uptake, followed by discussion of $M \Phi$-mediated drug metabolism and indirect effects on drug action via multicellular signaling. Growing abilities to contextualize M $\Phi$ imaging with scRNAseq promises to yield mechanistic insights and theranostic design opportunities.

\section{Mechanisms of material uptake by phagocytes}

Biologics, nanoparticles, and protein-bound small molecule drugs are generally internalized into cells via endocytosis pathways of phagocytosis (endocytosis of $>500 \mathrm{~nm}$ diameter particles), macropinocytosis (fluid endocytosis, "cell drinking"), receptor-mediated (clathrin-mediated) endocytosis, and calveolae. Although calveolae have been reported in subsets of myeloid cells such as certain $M \Phi$ populations in the lung [38], in general the expression 
of calveolins (CAV1-3) is much lower in immune cells [37]. Conversely, phagocytes are appropriately named for their high capacity for phagocytosis, and also display constitutive and regulated macropinocytosis and receptor-mediated endocytosis. Receptormediated endocytosis pathways are especially relevant to the pharmacokinetics (PK) of biologics and nanoparticles, and depend on several families of $\mathrm{M} \Phi$-expressed receptors.

\section{Pathways of receptor-mediated uptake.}

Scavenger and lipid receptors. $M \Phi$ remove aged reticulocytes and recover iron, which is essential for heme-containing cytochrome and metalloflavoprotein (e.g. xanthine oxidase) enzymes that metabolize most small molecule drugs [39]. The hemoglobin scavenger receptor CD163 (scavenger receptor cysteine-rich type 1 protein, SCARI1) is a M $\Phi$ lineage marker found on inflammatory and tissue-resident $M \Phi$ [35]. Anti-CD163 mAbs have been used to deliver drugs to $\mathrm{M} \Phi$ both by antibody-drug-conjugate (ADC) and nanoparticle formulations [40, 41]. $\mathrm{M} \Phi$ engulfment of aged red blood cells can divert iron into transferrin for immediate systemic release, or ferritin for storage and slow release, and this decision influences systemic iron levels [42]. Iron scarcity increases expression of transferrin receptor, an iron-shuttling protein whose transit across the blood-brain barrier has been extensively studied as a bispecific antibody target to carry cargos for central nervous system applications [43].

Intolerance to oral ferrous sulfate requires some iron deficient patients to receive parenteral iron dextran or polymerized carbohydrate:iron emulsions. The paramagnetic properties of such agents have allowed researchers to study $M \Phi$ distribution, abundance, and function non-invasively using magnetic resonance imaging (MRI), as reviewed previously [19]. The receptors responsible for the uptake of iron-containing particulates are many, as $M \Phi$ are specialists in recognizing carbohydrate motifs such as chitin, mannose, nucleic acids, and polyglucose [44, 45]. For instance, inhibition of macrophage scavenger receptor 1 (MSR1, also known as CD204 and scavenger receptor type AI/II, SR-AI/II; Fig. 1) has been shown to block uptake of the dextran-coated nanoparticle ferumoxytol mentioned above, and MSR1 interaction is linked to the anionic carboxymethyl groups of ferumoxytol [46]. scRNAseq from lung cancer biopsies suggest MSR1 is expressed across multiple M $\Phi$ subsets, but at lower levels in other phagocytes including monocytes, dendritic cells (DCs), and neutrophils (Fig. 1b-d). Another example M $\Phi$ imaging agent is Macrin, a polyglucose nanoparticle with similarities to ferumoxytol in size, shape, and carboxymethyl dextran composition. Macrin has been used to image tissue M $\Phi$ by PET/CT with $>90 \%$ selectivity via ${ }^{64} \mathrm{Cu}$ radiolabeling (Fig. 2) [15]. Its accumulation in untreated and cytokine-treated $M \Phi$ demonstrates its utility for labeling $\mathrm{M} \Phi$ regardless of the cell state [15].

$M \Phi$ activity varies across a spectrum of activation states regulated by signaling and pattern recognition cues [47]. A diverse set of polarization states can be identified in TAM by scRNAseq (Fig. 1a), yet for simplicity they are typically referred to along an M1/M2 dichotomy. The pro-inflammatory "M1" phenotype, often described as an antigen-presenting subset linked to better prognosis in solid tumor settings, is induced by inflammatory signals such as tumor necrosis factor alpha (TNFa), toll-like receptor (TLR) ligands, and the NFkB (nuclear factor kappa-light-chain-enhancer of activated B cells) pathway. In contrast to pro-inflammatory $M \Phi$, alternatively-activated "M2-like" $\mathrm{M} \Phi$ arise in wound-healing responses, are frequently found in tumors, and are more generally immunosuppressive given their moderate presentation of antigen and secretion of factors that limit $\mathrm{T}$ cell expansion $[48,49]$.

Transcriptional studies of M2-like $M \Phi$ have identified the mannose receptor MRC1 as a useful marker to distinguish this population from M1-like M $\Phi$ [50]. Chitin itself, an essential structural biopolymer of fungi, helminth and crustaceans, can alternatively activate and polarize $M \Phi$ from immature into M2 states[51]. The activity of C-type lectin receptors [52] likely influences the body's response to nanoparticles whose formulations include ligands for these receptors. Given the differences in scavenger receptor expression in different inflammatory contexts, special attention should be paid to ensure the proper $\mathrm{M} \Phi$-homing strategy is employed.

$\mathrm{M} \Phi$ accumulation in the cholesterol-rich regions of atherosclerotic plaques has led to further research into the impact $M \Phi$ play in lipid scavenging and metabolism. MSR1 recognition of oxidized low-density lipoprotein (LDL) regulates the activation of antigen presenting cells in the central nervous system and in cardiovascular plaques [53]. Unregulated uptake of lipids by atherosclerotic M $\Phi$ exacerbates disease and has sparked interest in nanoparticles to saturate MSR1 and its close relative CD36 (also known as scavenger receptor class B member 3, SCARB3) to block foam cell formation [54, 55]. These scavenger receptors have also been co-opted into imaging contrast agents for cardiovascular diagnostics [56]. In oncology, a myeloid signature containing MSR1 and CD163 was predictive of hepatocellular carcinoma prognosis [57]. From the therapeutic angle, synthetic HDL-based 
nanoparticles have been used to deliver paclitaxel to scavenger receptor class B type 1 (SRB1)-expressing cells [58]. The accumulation of fatty acids into lipid droplets is an early indicator of cell stress, and can lead to the sequestration of lipophilic drugs and exacerbation of chemoresistance $[59,60]$. Lipid uptake therefore offers both an avenue and a roadblock for therapeutic intervention.

The impact of lipid scavenging receptors on local immune responses can differ depending on context. For example, a DC-targeted nanoparticle vaccine was found to induce CD36 and interleukin 10 (IL10), leading to the counter-intuitive suppression of the adaptive immune response [61]. Macrophage receptor with collagenous structure (MARCO) is another pattern recognition receptor and lipid scavenger, whose expression has been found by single cell transcriptomics on both alveolar and monocyte-derived $M \Phi$ subsets in the lung [62]. The observation of MARCO expression on M2 TAM led researchers to develop an agonist MARCO mAb, which increased the efficacy of anti-CTLA4 therapy in an FcyR2b-dependent manner [63]. MARCO has been shown to be involved in the uptake of many advanced materials, including silver nanoparticles [64], carbon nanotubes [65], dextran-coated superparamagnetic oxide nanoparticles [66], and polystyrene particles [67]. For gene therapy, cellular uptake of lipid nanoparticle delivery systems relies on physical association with apolipoprotein E (ApoE) and lipoprotein receptors. The LDL receptor (LDLR) and LDL receptor-related protein 1 (LRP1) receptors, for instance, substantially contribute to uptake of siRNA-encapsulated lipid nanoparticles [68]. During the design of gene therapy systems careful attention also needs to be paid to foreign body responses, as in vivo modification of nanoformulations can affect their distribution, efficacy, and safety.
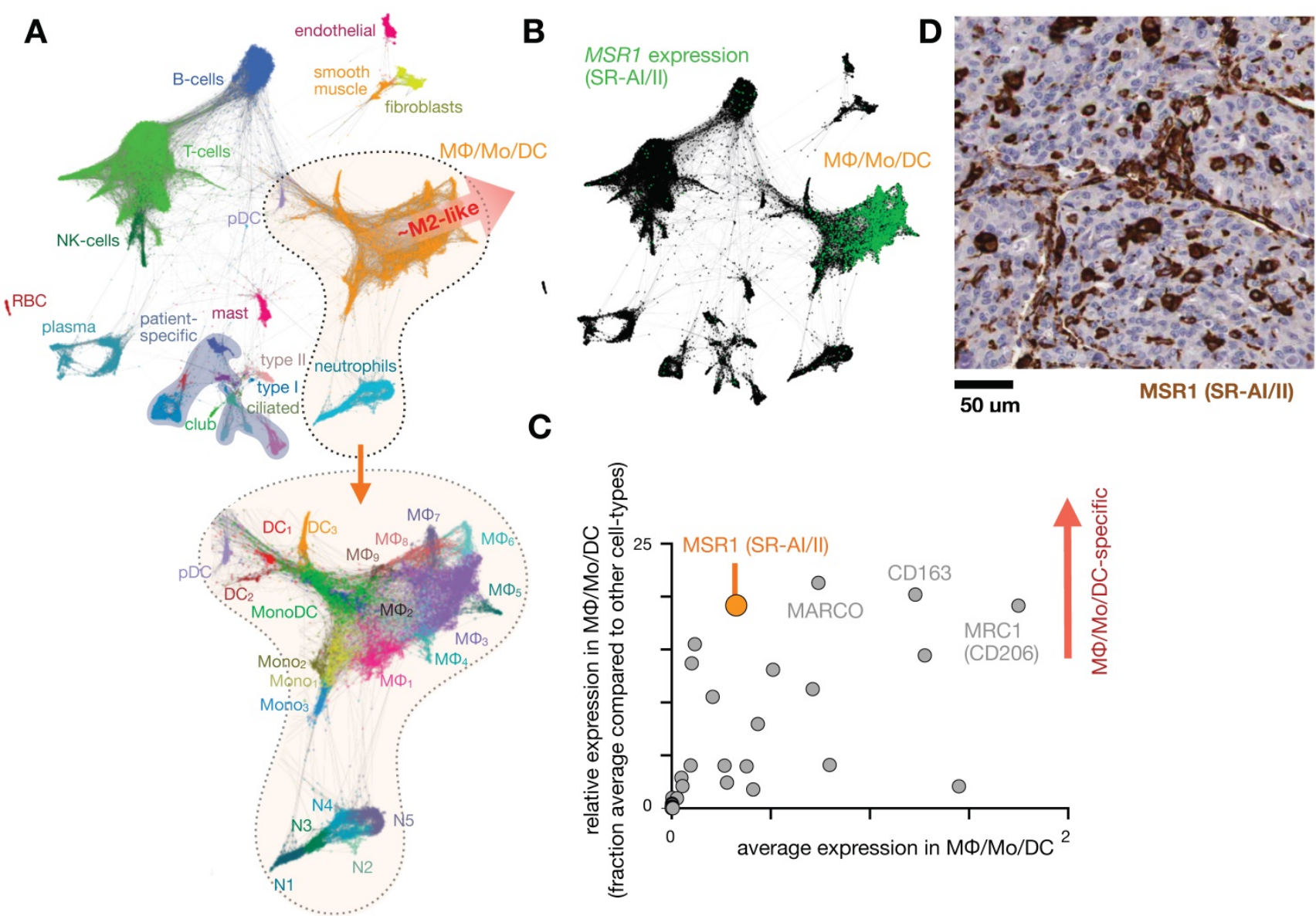

Figure 1. Expression of scavenger receptors in lung tumors. A) Single-cell RNAseq was pooled from 7 patients with lung cancer and automatically clustered according to gene expression profile (and thus cell-type) using the SPRING algorithm. Each data point represents a single-cell. At bottom, magnification of the MФ/monocyte/DC cluster can be further categorized into polarization subtypes. From GSE127465 and SPRING analysis in [37]. B) Corresponding to A, expression of the scavenger receptor type a (SR-Al/II, also known as MФ scavenger receptor 1, MSR 1 ) is shown in green. C) From data in A, a panel of 30 scavenger receptors [194] is plotted as a function of average ( $\mathrm{x}$-axis) and relatively selective (y-axis) expression in the M $\Phi / M o / D C$ cluster. $D)$ Immunohistochemistry of MSR1 in a biopsied lung adenocarcinoma, showing staining consistent with myeloid expression (from the Human Protein Atlas v19.3 [195]). 

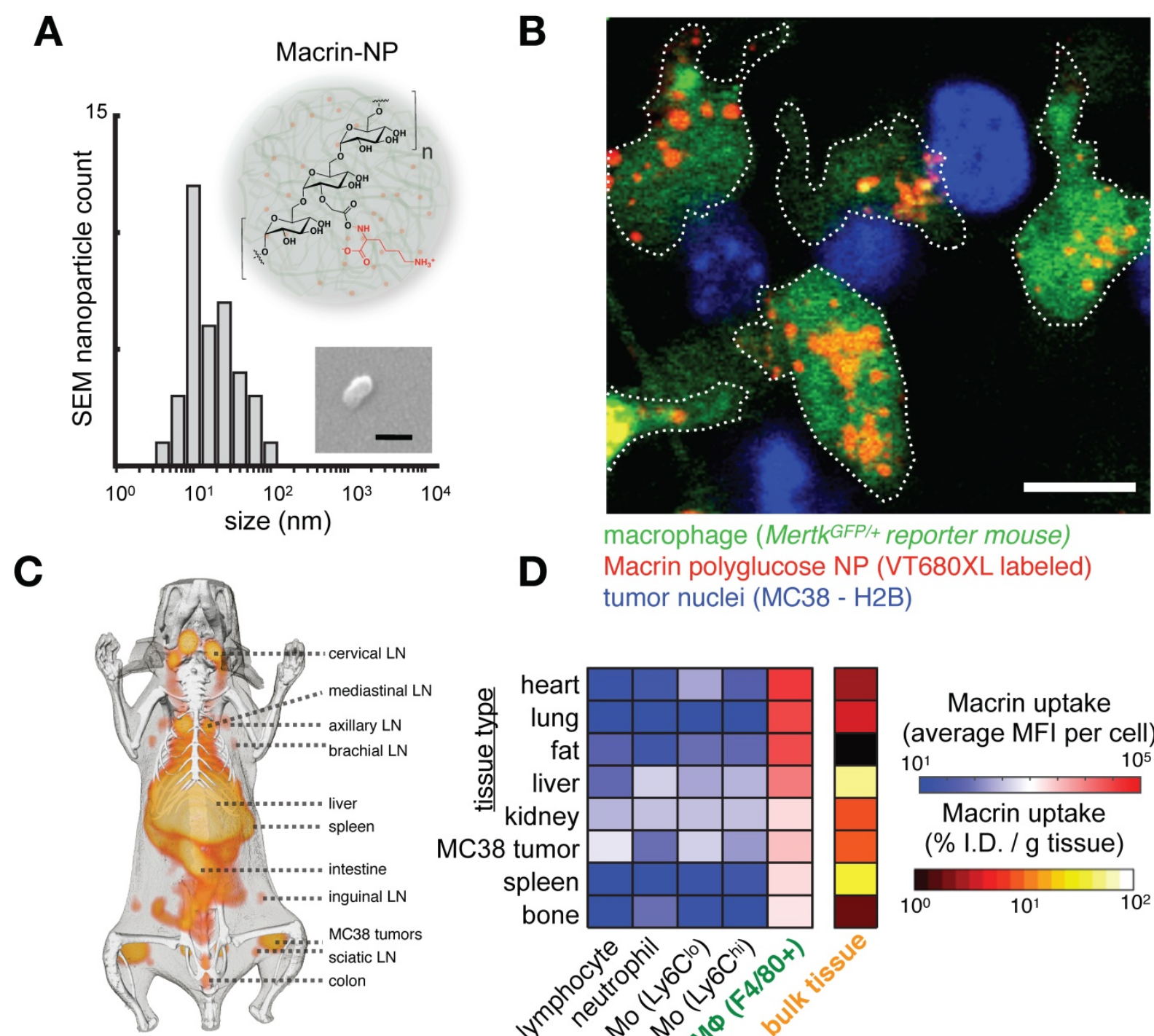

\section{Macrin polyglucose NP (VT680XL labeled) tumor nuclei (MC38 - H2B)}
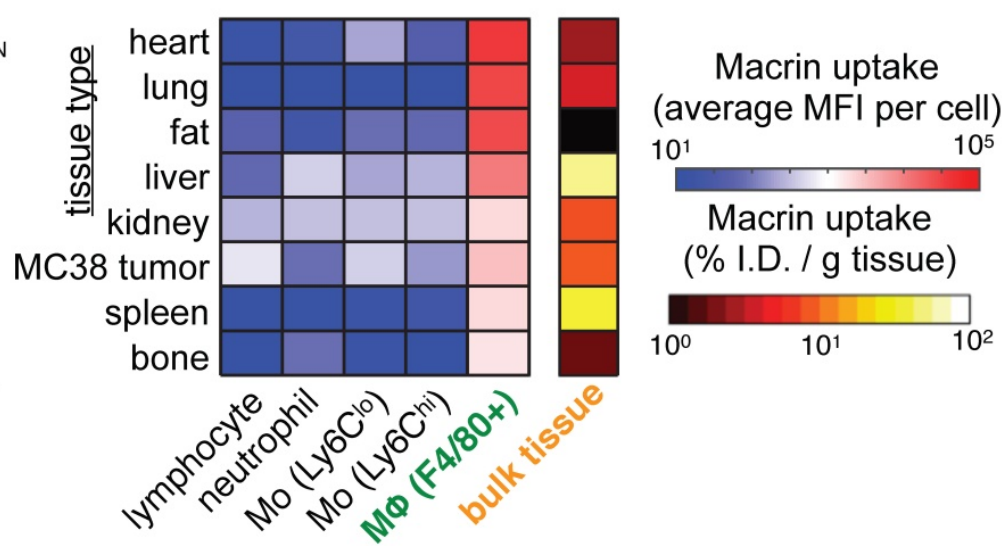

Figure 2. The dextran-based nanoparticle Macrin accumulates selectively in $M \Phi$ in tumor and healthy tissue. A) Scanning electron microscopy of Macrin, a $\sim 20$ $\mathrm{nm}$ diameter crosslinked polyglucose nanoparticle that can be labeled with fluorescent probes or the radionuclide ${ }^{64} \mathrm{Cu}$. Scale bar, $20 \mathrm{~nm}$. B) Confocal microscopy shows selective Macrin accumulation in tumor associated $M \Phi$, in tumors growing in the MertkGFP/+ reporter mouse model, which contains GFP+ MФ. Scale bar, $10 \mu m$. C) Positron emission tomography / X-ray computed tomography (PET/CT) of ${ }^{64} \mathrm{Cu}$-labeled Macrin in mice bearing MC38 tumor allografts. D) Using the same allograft model, fluorescent Macrin was analyzed for uptake on a per-cell basis by flow cytometry. In all tissues, Macrin accumulation was highest in $M \Phi$, and total organ uptake correlated with M $\Phi$ density in tissues rather than uptake on a per-cell basis. All adapted with permission from [15], copyright 2018.

Fc receptors. Antibodies consist of fragment antigen-binding ( $\mathrm{Fab}$ ) variable regions at their head and a constant fragment crystallizable $(\mathrm{Fc})$ region at their stem. The $F_{c}$ region binds complement proteins and cell receptors, including $F_{c}$ receptors (FcRs) on immune cells (Fig. 3). Immune responses to antibody-bound antigen are tailored by the antibody class and its avidity for each of the 11 total FcRs in humans. Antibody-producing B cells undergo class switching to control the immunoglobulin (Ig) isotype (IgA1-2, IgD, IgE, IgG1-4, and IgM) and its corresponding effector function. Each Ig isotype differs in its avidity for each FcR, introducing a complexity suitable for handling diverse pathogenic challenges. For therapeutics, subclasses of the IgG type are used with few exceptions. IgG antibodies communicate neutralizing instructions through the Fc-gamma receptor $\left(F_{c} \gamma R\right)$ family, the members of which exhibit distinct avidity for IgG subclasses and distinct downstream activities. IgG antibodies are long-circulating, have a well-understood manufacturability, and contain a diverse enough repertoire of effector functions such that antibody-dependent cell-mediated cytotoxicity (ADCC), phagocytosis, complement recruitment, signal blockade, and even receptor agonism can be achieved with this isotype alone [69].

FcRn. Monoclonal antibodies (mAbs) are constantly internalized and recycled by cells due to a mechanism wherein acidic intracellular conditions thermodynamically favor neonatal $\mathrm{Fc}_{\mathrm{c}}$ receptor ( $\mathrm{FcRn}$ ) binding, leading to exocytosis, diminished FcRn 
affinity at neutral $\mathrm{pH}$, and recirculation. This process contributes to the long circulation half-lives $(>3$ weeks) of most $\mathrm{mAb}$ therapies, and has inspired the common practice of $\mathrm{Fc}$-fusion for extending circulation [70]. Albumin also binds FcRn, and consequently albumin binding is a successful strategy to extend PK of therapeutics [71] and imaging agents [72]. FcRn expression has been observed on the endothelial cells that line blood vessels as well as the serum-sampling perivascular $M \Phi$ that help shape vessel structures [73]. FcRn expression on gut epithelial cells has been used to orally deliver IgG-Fc coated nanoparticles for systemic distribution [74]. Recently, scRNAseq has made possible detailed queries into FcRn involvement in local, diseased tissues (Fig. 3). Efgartigimod, one of several FcRn blocking agents at various stages of development, has shown efficacy in a Phase III trial to treat the autoantibody-driven immune disorder myesthenia gravis (NCT03770403) [75]. New insights into FcRn involvement in local distribution of therapeutic $\mathrm{mAb}$ requires development of $\mathrm{mAb}$ labeling techniques that don't interfere with the FcRn binding domain of the $\mathrm{Fc}$ region, although labeled albumin can be a useful surrogate [76].
FcyR. mAb effector activity is carried out by proteins and $F_{c \gamma} R$-expressing cells that recognize the $\mathrm{Fc}$ region of an antigen-bound $\mathrm{mAb}$ (Fig. 3a-c). The high-affinity $F_{C} R, \quad F_{C \gamma R} 1$ (CD64), tightly binds monovalent $\mathrm{IgG}$, is expressed highest on $\mathrm{M} \Phi$, and has been described as a reliable $M \Phi$-specific marker in both mouse and human transcriptomic studies [77]. In contrast, $\mathrm{F}_{c \gamma R} \mathrm{R} \mathrm{a}$ and $\mathrm{F}_{\mathrm{c}} \mathrm{R} 3 \mathrm{3}$ have higher binding affinities for IgG that have clustered into immune complexes[78]. FcyR3a (CD16) is commonly included in flow cytometry staining panels for NK cells, however, this would not be a reliable target for NK imaging agents as scRNAseq suggests multiple myeloid populations to also be high expressers (Fig. 2). These activating Fc receptors are the promoters of antigen-destruction pathways because they convert adaptive immune signals (e.g. IgG1s) to recruit innate immune cell killing. Not all mAbs form effective low-affinity $\mathrm{F}_{\mathrm{c}} \mathrm{R}$-activating immune complexes, and some (e.g. IgG4, deglycosylated mAbs, Fc-null or Fc-effectorless mAbs) act instead to bind and block extracellular signal transmission [79]. $F_{c \gamma} R 2 b$ is unique in that it has an ITIM (immunoreceptor tyrosine-based inhibition motif) domain in place of the activating ITAM (immunoreceptor tyrosine-based
A

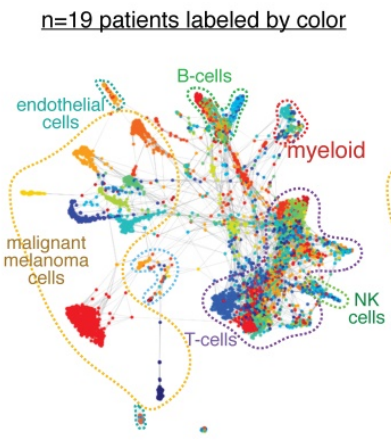

C

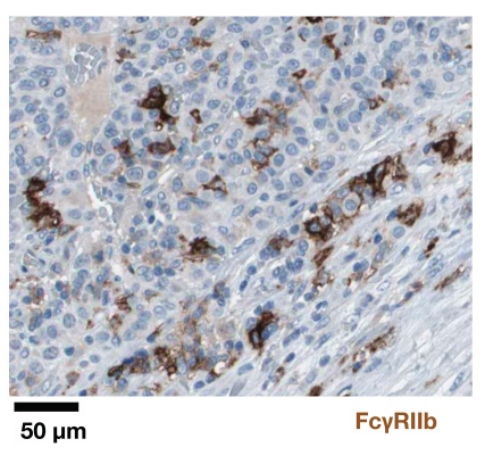

PD1 expression

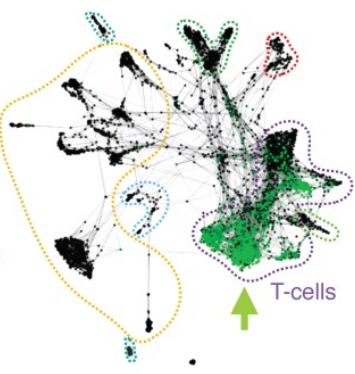

D
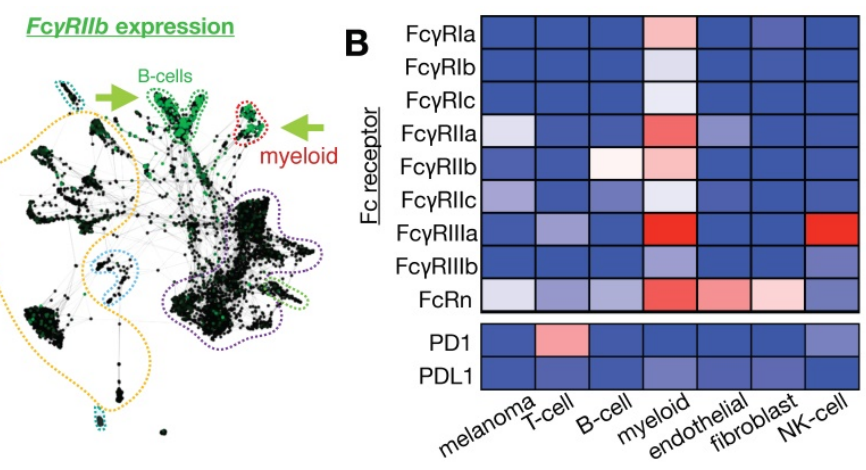

cell-type

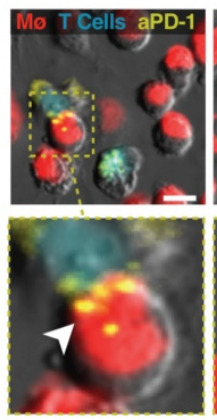

-FcyRIIIIII block
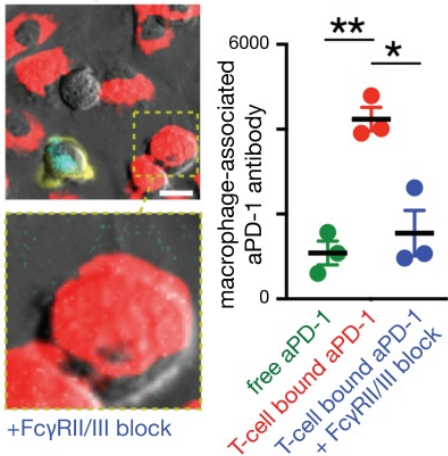

average gene expression (a.u.)

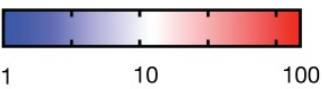

Figure 3. Fc receptors are highly expressed in myeloid cells and can impact the cellular biodistribution of an anti-PDI therapeutic antibody. A) Single-cell RNAseq data from $>4,500$ cells of melanoma biopsies was clustered according to gene-expression (and thus cell-type), and expression of PDI and FcyR2b are shown by green color. In this patient cohort, expression of the target of nivolumab, an IgG4 anti-PDI antibody, is primarily found in T-cells, while its inhibitory Fc receptor FcyR2b is primarily found in B-cells and myeloid cells, including MФ. Figure adapted with permission from [11] using scRNAseq data GSE72056 [28], copyright 2020. B) Average expression values corresponding to single-cell data in $A$. C) Immunohistochemistry of a melanoma metastasis to the pancreas shows high FcyR2b expression in cells consistent with infiltrating myeloid cells (from the Human Protein Atlas v19.3 [195]). D) 30 minute time-lapse microscopy of co-culture using PD 1+ T-cells, M $\Phi$, and anti-PD1 antibody shows transfer of antibody to $M \Phi$ from T-cells that were pre-treated with the antibody, in a FcyR2/3 dependent manner. Scale bar $10 \mu \mathrm{m}$. Adapted with permission from [80], copyright 2017. 
activation motif) found on the intracellular region of most FcyRs. Expressed in B cells and myeloid cells (Fig. 2), $\mathrm{F}_{\mathrm{c}} \mathrm{R} 2 \mathrm{~b}$ is an inhibitory receptor capable of binding and mechanically engaging mAb-bound receptors, without activating a destructive immune response against the antigen in question. In mice, tumor associated $\mathrm{M} \Phi$ (TAM) express especially high FcyR2b [63], and imaging studies have found that TAM can strip an anti-PD1 mAb from the surface of $\mathrm{PD} 1+\mathrm{T}$-cells in a FcyR2/3-dependent process (Fig. 3d) [80]. In vivo tumor imaging revealed anti-PD1 mAb initially on PD1+ T-cells, but showed a gradual shift to accumulation within TAM. FcyR blockade enhanced anti-PD1 response in the corresponding mouse allograft model [80]. Similar imaging studies with fluorescently-labeled anti-HER2 mAb trastuzumab have found initial accumulation on HER2+ cells, but by 2 days after injection, the localization was primarily in TAM rather than tumor cells (Fig. 4) [81]. The mAb isotypes used in these studies were distinct, as were mouse strains, and FcR-dependencies therefore are likely to be different. Future work needs to map how isotype and Fc-engineering influence TAM uptake dynamics and productive effector functions such as ADCC and antibody-dependent cell phagocytosis. Molecular imaging to selectively study $\mathrm{F}_{\mathrm{c}} \mathrm{R} \mathrm{R} 2 \mathrm{~b}$-expressing cells would be useful for engineering better non-depleting agonist mAbs.

MФ polarization-influenced FcR activity. Pro-inflammatory signals can upregulate M $\Phi$ FcRn expression and thus accelerate the rate of $\mathrm{mAb}$ recycling in M1-like M $(\mathrm{IFN \gamma})$, a key signal in the induction of pro-inflammatory phenotypes, influences the fate of internalized material. $\mathrm{M} 1-\mathrm{M} \Phi$, partly due to their higher IFN $\gamma$-induced nitric oxide synthase 2 (NOS2) expression, generally are slower to degrade phagocytosed material [83]. Endocytosis can occur through $F_{c} \gamma R$ binding, and FcRn, in this instance, salvages $F_{c} \gamma R$-bound antigens to ensure processing for MHC loading and presentation to the adaptive immune system [84]. MHC expression is also IFN $\gamma$-inducible, and the loss of antigen presentation machinery in TAM has led to many "re-polarization" efforts for solid tumor therapy $[85,86]$. In contrast to pro-inflammatory $\mathrm{M} \Phi$, IL-4 induces precursor monocytes to mature M2-like $\mathrm{M} \Phi$ and counteracts IFN $\gamma$ by lowering $\mathrm{Fc}_{\mathrm{c}} \mathrm{R} 1$ expression [87]. The kinetics of phagosomal acidification and proteolysis are faster in $\mathrm{M} 2-\mathrm{M} \Phi$, and $\mathrm{pH}$-sensitive materials have been used as imaging agents for this subset [88, 89]. М $\Phi$ polarization also influences expression of other degradative components including proteases [90].
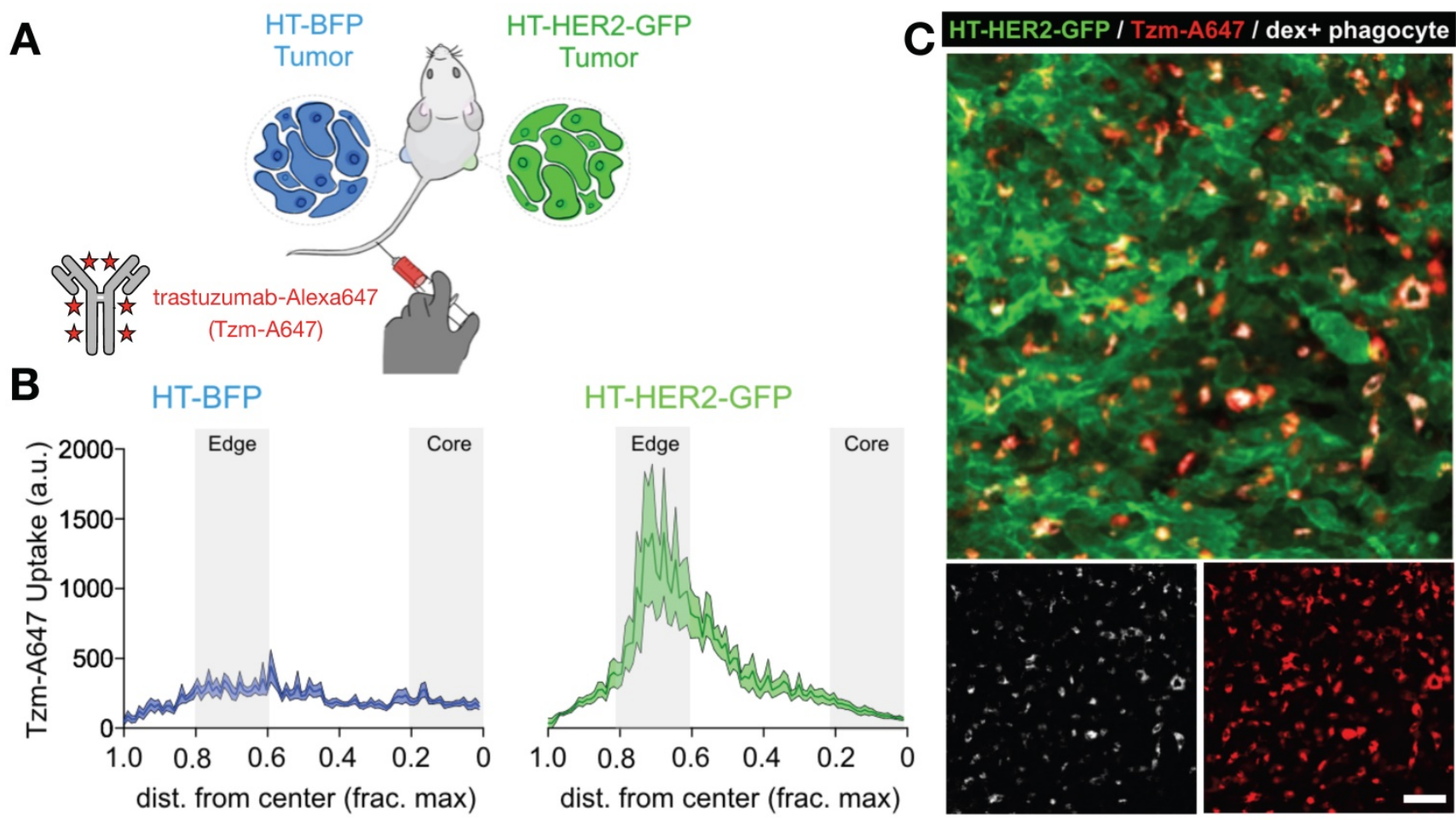

Figure 4. Matched HER2+ and HER2- xenografts show target-dependent and -independent antibody uptake into tumor associated phagocytes. A) Contralateral xenografts were grown either with transgenic expression of a HER2-GFP fusion protein (HT-HER2-GFP), or with blue fluorescent protein lacking HER2 as a control (HT-BFP). Fluorescently labeled anti-HER2 antibody trastuzumab (Tzm-AlexaFluor647) was injected intravenously and tissue was collected the following day. B-C) Quantification (B) and corresponding representative confocal microscopy (C) revealed that trastuzumab accumulated in both tumor-types, but at higher levels in the HER2+ tumors. However, by $24 \mathrm{~h}$ most antibody was in phagocytes including MФ, rather than on HER2+ tumor cells. Scale bar, $50 \mu \mathrm{m}$. Adapted with permission from [81], copyright 2020. 
A

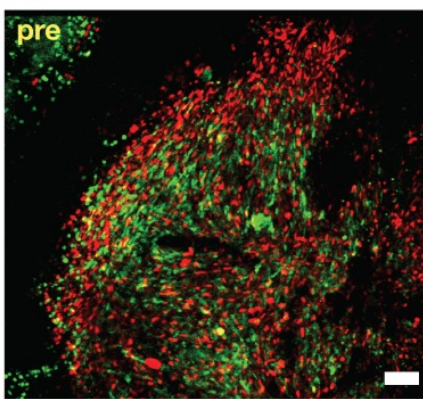

tumor cells (MC38 H2B-mApple) Arg1+ cells

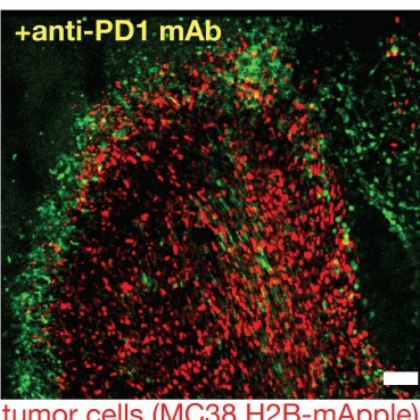

Arg1+ cells

C

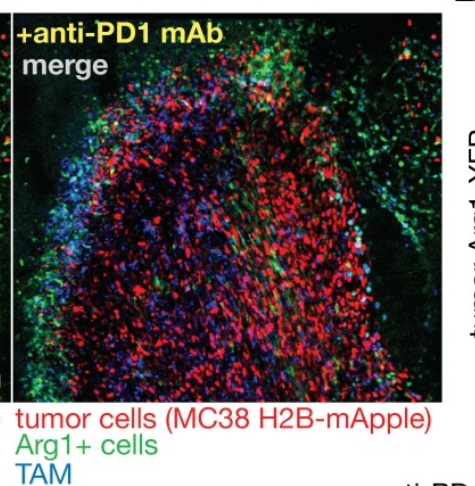

B

anti-PD1 mAb:

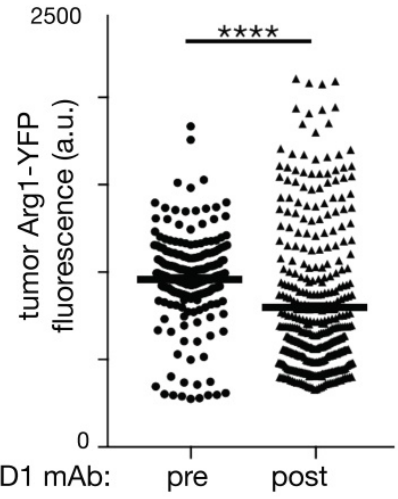

D
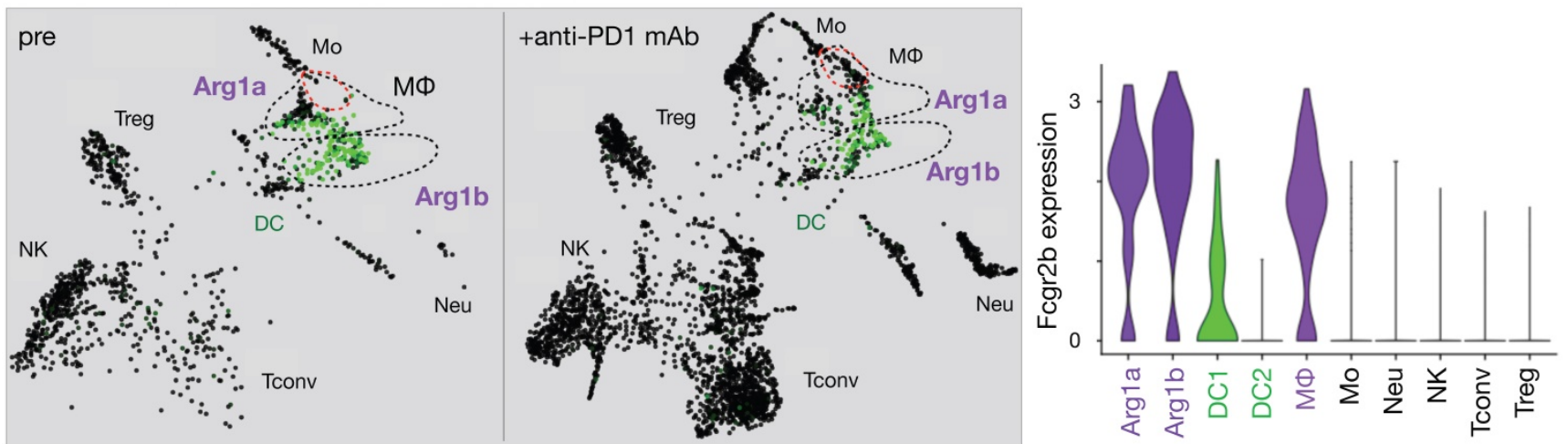

Figure 5. Immune checkpoint blockade shifts TAM polarization and spatial infiltration. A-B) Intravital microscopy was used to assess allografts of the MC 38 cancer cell line growing in a genetic reporter mouse model where yellow fluorescent protein was driven by arginase 1 (Arg1) promoter activity. Images before and 3 days after anti-PD1 antibody treatment show decreased Argl expression. Scale bar, $100 \mu \mathrm{m}$. C) The SPRING algorithm was used to cluster scRNAseq using the same allograft model into immune cell-types, revealing Argl expression (green) primarily in TAM subsets labeled Argl a and Arglb. D) Violin plots from scRNAseq data show both Argla and Arglb subsets express high levels of Fcgr2b compared to other immune subsets. Adapted with permission from [94], copyright 2018.

M $\Phi$ activation states have been transcriptionally defined, and IL12b and Arg1 have been used to define M1-like and M2-like $M \Phi$, respectively, in mice [91, 92]. In vivo confocal (intravital) microscopy of tumors embedded intradermally in IL12-eYFP reporter mice revealed the additive effect M1-inducing therapies can have when delivered in combination with immune checkpoint blockade using anti-PD-1 mAb [93]. Conversely, effective anti-PD-1 response was observed by intravital microscopy to include replacement of Arg1-expressing TAM with highly-motile pro-inflammatory monocytes and M1 precursors (Fig. 5) [94]. Despite observed differences in polarization, both Arg1-expressing subsets were found to exhibit high FcyR2b expression (Fig 5).

Complement Receptors. Complement factors are another means by which a particle or cell can be marked for phagocytosis. Upon injection, nanoparticles form a protein corona as they interact with serum proteins that adsorb on their surface [95]. As the protein corona evolves, particle opsonization with complement proteins can stimulate phagocytosis. $\mathrm{C} 1 \mathrm{q}$ is a component of the classical complement pathway and is one of the strongest differentially-expressed genes that distinguishes pro-inflammatory $\mathrm{M} \Phi$ from their tolerogenic counterparts in the liver [35]. C1q has a broad range of binding partners including $\operatorname{IgG}, \operatorname{IgM}$, and phosphatidylserine (PS), and its role in clearing apoptotic cells is critical for prevention of autoimmunity [96]. Complement recruitment is a major effector function by which the anti-CD20 mAb rituximab works in the treatment of B-cell malignancies and autoimmune disorders, but it also represents a source of heterogeneity in the effectiveness and occurrence of adverse events among patients [97, 98]. In part to address this issue, an anti-CD20 mAb obinutuzumab was Fc-engineered to bypass complement-directed cytotoxicity and was shown by intravital microscopy to enhance the antibody-directed phagocytosis of B lymphoma cells by Kupffer cells, a liver-resident macrophage population [99]. Alternative opsonins to C1q, such as mannose-binding lectin, also exist. Myeloid cells serve as innate immune effectors for the complement pathways and express receptors that can initiate chemotaxis, phagocytosis, and degranulation activity. Platelet activation through complement can cause fatal intravascular coagulation and has been shown to have a major influence on nanomaterial 
hypersensitivity [100, 101]. Cationic surfaces exacerbate this hemolytic effect and enhance corona formation, thus a slight negative charge usually imparts stronger tumor-homing capabilities [6]. Corona and complement formation also offer an indirect avenue through which material uptake by MФ can occur.

Efferocytosis receptors. When a red blood cell ages, it expresses many of the ligands for phagocyte scavenger receptors discussed in previous sections. Additionally, loss of the "don't eat me" signal CD47 overcomes any remaining SIRPla-mediated inhibition and permits the engulfment of the aged cell and recycling of its components. This pathway is co-opted by malignant cells as a means of immune evasion and has inspired CD47-blocking mAb clinical stage programs from several companies (NCT0 2953509; NCT03512340; NCT02641002; NCT03013218; NCT02663518; NCT02890368; NCT03530683). CD47 and other marker-of-self signals have also been used to shield nanoparticles to extend circulation [102]. When not blocked by don't-eat-me signals, phagocytes respond to PS on the outer bilayer of aged and apoptotic cells by initiating efferocytosis. PS is recognized by a range of receptors and its effects on the phagocyte have been observed to be broadly immunosuppressive [103]. TIM1, TIM3 and TIM4 are known PS receptors whose blockade in mice caused autoantibody formation [104]. At least 10 other receptors have been described, many highly expressed on $M \Phi$, including the CD300 family and STAB1/2 that directly bind PS. Although not through direct binding, the TYRO3/AXL/MERTK family efferocytosis receptors can be engaged indirectly when bridged by the GAS6 and PROS1 serum proteins, and $\mathrm{mAb}$-based tools have been developed for in vivo imaging of AXL [105]. Genetic defects in Mertk can lead to defunct debris clearance and formation of necrotic plaques in mice [106]. MERTK has an immunosuppressive effect when engaged on $\mathrm{M} \Phi$, and several inhibitors in development have reached clinical trials (NCT01482195; NCT03176277; NCT03176277). One such clinical candidate, UNC-2025, was tagged with a silicon rhodamine and used as an imaging agent to study MERTK receptor distribution in mouse tumor allografts and metastases, revealing high TAM accumulation (Fig. 6) [107].

\section{Macropinocytosis}

Macropinocytosis is an endocytic process that allows cells to non-selectively internalize extracellular fluid, solutes, and antigens. It is an evolutionarily conserved form of endocytosis that can be carried out by nearly all types of cells inside the body, including innate immune cells, fibroblasts, epithelial cells, and neurons [108]. Macropinocytosis can influence the PK of therapeutic agents, as drugs dissolved in the extracellular space can be non-selectively taken up by cells through this process [109]. Macropinocytosis is primarily driven by actin cytoskeleton rearrangement near the plasma membrane [110], which results in the folding back of the membrane to create endocytic vesicles $0.2-5 \mu \mathrm{m}$ in size. These large endocytic vesicles are called macropinosomes, and they allow the cells to efficiently take up large quantities of extracellular materials, including drugs [111].

Signaling molecules involved in actin remodeling, such as Ras, PI3K, Rac1, Cdc42, and Pak1 influence macropinocytosis [111]. Moreover, sorting for the nexin (SNX) family of membrane proteins and C-terminal binding protein ( $\mathrm{CtBP})$, which controls membrane trafficking, have been implicated in macropinosome formation [111, 112]. Proteins involved in endosomal regulation, such as Rab5 and Rab34, have been shown to associate with macropinosomes [111]. Regulators of cellular metabolism, such as AMPK and mTOR, can also influence macropinocytic activity, since cells can use macropinocytosis to take up nutrients and abundant proteins such as albumin in the extracellular space. Functional genetic RNA interference screens have been used to systematically identify regulators of macropinocytosis in RAS-driven cancer cells and $M \Phi$, providing broad perspective into underlying regulatory processes [113]. For instance, macropinocytosis contributes to the uptake of low density lipoprotein (LDL) as M $\Phi$ transform into foam cells during atherosclerosis [114], and a functional genetic screen showed pathways involved in LDL uptake and foam-cell generation, including CSF1R, CXCR4, and involvement of APOC1 and FABP4 [115]. While macropinocytosis transcriptional signatures have been linked to drug outcomes, these bulk analyses are unable to elucidate the specific contribution of $\mathrm{M} \Phi$ to this pharmacology [116].

Macropinocytosis can be stimulated by growth factors in many cell types [110], yet can be constitutive in RAS-mutant cancer cells [117] and some subsets of MФ [118] and DCs [110]. Macropinocytosis mediates immune cell functions such as antigen scavenging and presentation by $M \Phi$ and DCs [118], chemotactic migration of neutrophils [119], and proliferation of T cells [120]. Macropinocytosis in particular has been shown to mediate uptake of nanomaterials, including lipid nanoparticles (LNPs) [121] and silica-based nanoparticles [122]. For instance, it controls the uptake of RNA vaccine by immature DCs in lymph nodes [123]. The uptake of viral vaccine vectors by antigen presenting cells, a crucial step in 
vaccine-induced immunity, is also mediated by macropinocytosis [124]. One recent study demonstrated that macropinocytosis drives the uptake of nanoparticulate albumin-bound paclitaxel (nab-paclitaxel, marketed as Abraxane and FDA-approved for treatment of pancreatic adenocarcinoma and other cancers) by TAM, leading to the activation of pro-inflammatory phenotypes in these cells [125]. Furthermore, M2-M $\Phi$ have been reported to exhibit enhanced macropinocytosis activity compared to those with a pro-inflammatory M1 phenotype [126]. Thus, the polarization state of MФ can impact their macropinocytic activity, which may have ramifications in designing therapeutics to target select $\mathrm{M} \Phi$ subsets.

\section{Small molecule transporters.}

Membrane transporters fall into classification as ATP-binding cassette transporters (ABC transporters), solute carrier family (SLC) transporters, and the superfamily of P-type ATPases. The latter family consists of flippases responsible for maintaining asymmetric phospholipid cell membranes, and importantly ion pumps including ATPase copper transporting alpha and beta (ATP7A and ATP7B), which promote efflux of, and resistance to, the chemotherapeutic cisplatin [127]. However, these two genes are not typically expressed in leukocytes at high levels. ABC transporters are implicated in the PK of many drugs, and include family members MDR1 (P-glycoprotein) and MRP1 that can be found expressed in lymphocytes and drug-resistant cancer cells. Although phagocytes express relatively low levels of MDR1 and MRP1, M $\Phi$ express ATP-binding cassette transporter ABCA1 (cholesterol efflux regulatory protein, CERP) and ABCG1, which both govern homeostasis of cholesterol and phospholipids. Loss of ABCA1
A

B

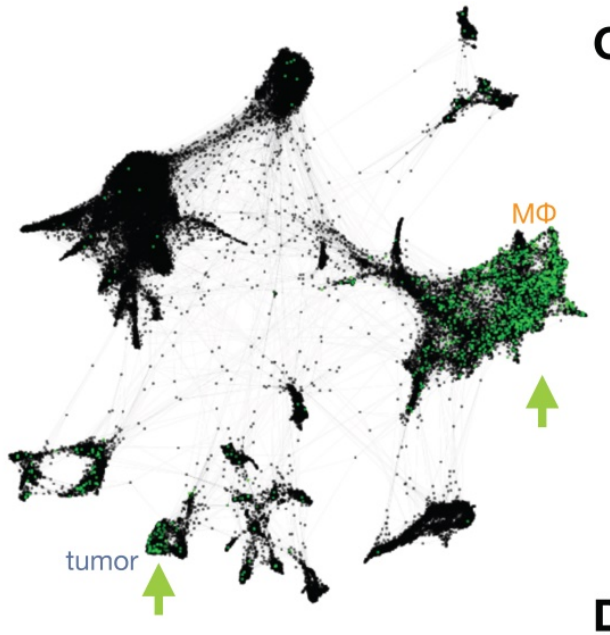

C

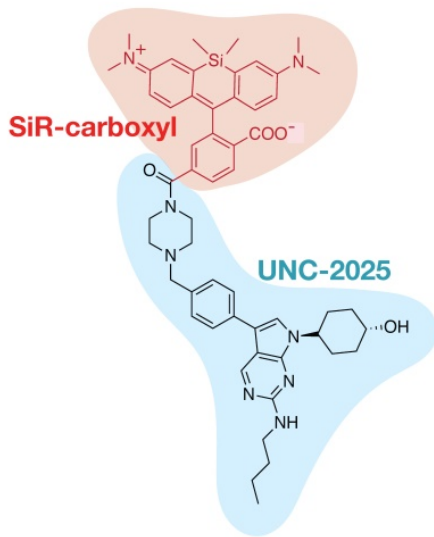

MERi-SiR

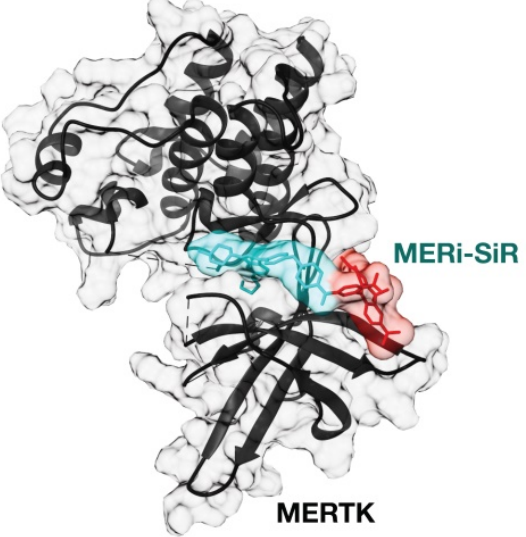

D
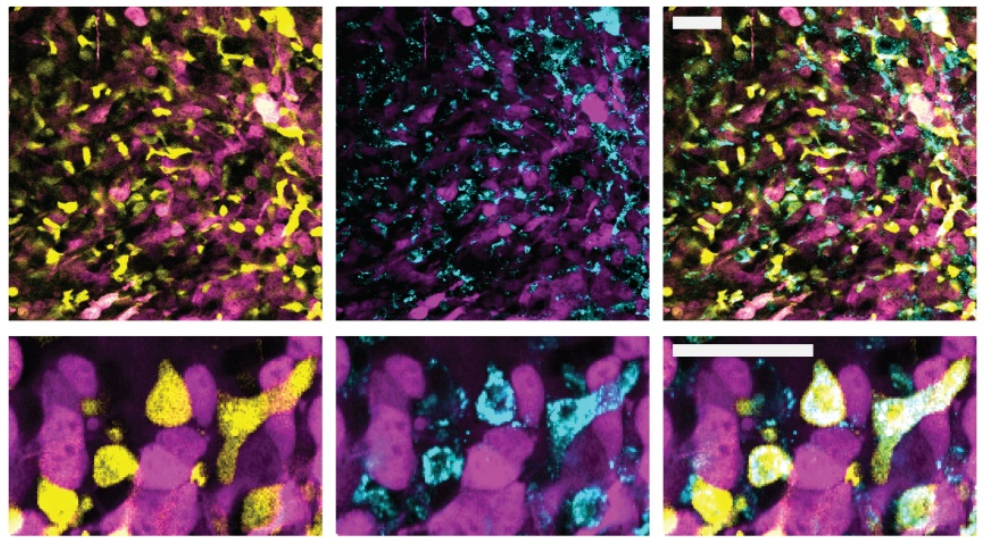

tumor cells (CT26-tdTomato)

TAM (GFP from MertkGFP/+ reporter)

MERi-SiR

Figure 6. Targeting the efferocytosis receptor MERTK to image MФ. A) As in Fig. 1, scRNAseq was pooled from 7 patients with lung cancer and MERTK expression is shown in green. Some patients show MERTK+ cancer cells, and MERTK is expressed across multiple MФ subsets. From GSE127465 and SPRING analysis in [37]. B) Example immunohistochemistry from a lung adenocarcinoma biopsy shows MERTK staining consistent with expression in stromal / myeloid cells rather than malignant cells (from the Human Protein Atlas v19.3 [195]). C) The MERTK kinase inhibitor UNC-2025 was modified with the near-infrared silicon rhodamine COOH (SiR) to yield the fluorescent probe MERi-SiR, shown in a docking simulation bound to MERTK. D) Confocal microscopy of CT26 allograft tumors in the MertkGFPI+ knock-in reporter mouse shows co-localization in GFP expression (which reports on Mertk expression) with uptake of MERi-SiR. Scale bar, $50 \mu \mathrm{m}$. C-D adapted with permission from [107], copyright 2017. 
function leads to the autosomal recessive Tangier disease characterized by abnormally low circulating levels of high density lipoprotein (HDL). ABCA1 has been reported to affect the local, cellular-level distribution of Amphotericin B, a polyene anti-fungal that binds preferentially to membrane sterols, particularly the fungal ergosterol but also cholesterol. ABCA1-expressing cells transport cholesterol to the cell surface where interaction is observed with Amphotericin B, leading to decreased cellular cytotoxicity, which is hypothesized to mitigate its toxic side effects [128].

Both neutrophils and M $\Phi$ express ABCG1, and in two independent studies [129, 130] SNPs of the ABCG1 gene were found to associate with toxicity of the chemotherapeutic irinotecan in patients with metastatic colorectal cancer. One study hypothesized this was not due to direct action on irinotecan, but rather to inflammation associated with defective ABCG1 activity, and unbalanced cholesterol homeostasis, as has been observed in mice and patients [130]. In the other study, the ABCG1associated toxicity was severe neutropenia [129]. ABCG1 is a confirmed transporter of the chemotherapies mitoxantrone and doxorubicin [131], and the pentacyclic ring structure of irinotecan bears similarity to the ring structures of other ABCG1 substrates.

In comparison to active transport by ATP hydrolysis, SLC transporters use secondary active transport and exploit the membrane potential of ions such as $\mathrm{Na}^{+}$or $\mathrm{H}^{+}$. These transporters move drugs across the plasma and organelle membranes. Organic anion transporting polypeptides (OATPs) including OATP1B1 and OATP1B3 are prominent in hepatic and intestinal transport. $\mathrm{M} \Phi$ express high levels of OATP2B1 (known as SLCO2B1), which is also known to be expressed in other tissues including the brush-border membrane of the small intestine and hepatocyte basolateral membranes [132]. OATP2B1 mediates $M \Phi$ uptake of the uremic toxin indoxyl sulfate, which is a metabolite of dietary tryptophan and elicits pro-inflammatory signaling and atherosclerosis lesion development in mice [133]. Hydroxymethylglutaryl-coenzyme A (HMG-CoA) reductase inhibitors including fluvastatin, rosuvastatin, and the antihistamine fexofenadine are OATP2B1 substrates according to recent reports that examined OATP2B1 knockout mouse models [134].

Expression of SLC15A4, also known as peptide/histidine transporter 1(PHT1), in myeloid cells is associated with transport of histidine, carnosine, and the antiviral prodrug valacyclovir [135]. Other SLC15 family members have also been examined as carriers of prodrugs including valacyclovir [136]. In myeloid cells SLC15A4 has been implicated in endolysosomal toll-like receptor (TLR) signaling, autoimmune disease, and downstream activation of the interferon regulatory factor 5 (IRF5) transcription factor which controls $M \Phi$ activation [137].

Multi-gene programs of MФ-expressed SLCs can be dynamically regulated during the phagocytic clearance of apoptotic cells and cell debris (efferocytosis), with prominent contribution noted from SLC16A1 (also known as monocarboxylate transporter 1, MCT1), which can export lactate from $\mathrm{M} \Phi$ undergoing aerobic glycolysis and contribute to an anti-inflammatory extracellular environment [138]. Proliferating T-cells also use aerobic glycolysis, rely on MCT1 for lactate efflux, and MCT1 inhibition can thus be immunosuppressive [139]. MCT1 has also been identified in a genome-wide functional screen to mediate uptake of the potential anticancer agent 3-bromopyruvate into cancer cells, where it can disrupt glycolysis [140], and MCT1 has been associated with the transport of drugs including bumetanide, valproic acid, nateglinide, salicylate, simvastatin and atorvastatin [141].

Phagocyte-selective expression of SLC transporters has been exploited to develop imaging probes (Fig. 7), as recently demonstrated with the fluorophore CDg16 found to accumulate in activated $M \Phi$ [142]. In this study, fluorescent compounds were first screened for selective accumulation in stimulated $M \Phi$, and functional CRISPR screening revealed uptake was dependent upon SLC18B1. The probe was effective in labeling $M \Phi$ within atherosclerotic plaques in $\mathrm{ApoE}^{-/-}$mouse aortas [142].

\section{Phagocytes and drug metabolism}

In addition to mere transport, $\mathrm{M} \Phi$ express enzymes that can participate in chemical drug transformation (Fig. 8a-c), and local $\mathrm{M} \Phi$ accumulation at sites of disease may allow prediction of corresponding local drug activity.

Proteases. Phagocyte-expressed reactive enzymes, including proteases, have been exploited for activation of nanoparticles, antibodies ("pro-bodies"), antibody drug conjugates, and small molecule prodrugs. scRNAseq data reveal distinct patterns of relevant protease expression across cell-types in the tumor microenvironment. In scRNAseq from a cohort of lung adenocarcinoma biopsies, neutrophils and TAMs are the primary expressers of cathepsin B (CTSB) [37]. Both neutrophils [143] and M $\Phi$ produce matrix metalloproteinase 9 (MMP9) [37, 144]. In contrast, other relevant proteases including MMP2 can be more highly expressed in cancer-associated fibroblasts than leukocytes [37]. MMP14 (also known 
as membrane type-I matrix metalloproteinase, MT1-MMP) can be expressed across a mix of fibroblasts, $M \Phi$, and tumor cells [37]. Among $M \Phi$, enrichment in tissue-resorbing cathepsins and proteolytic enzymes have been observed by scRNAseq in specialized M2-like wound-healing subsets [90]. These proteases and others participate in various disease processes, particularly with respect to remodeling of the extracellular matrix, and are drug targets themselves.

Translational imaging technologies have been developed to detect cathepsin and metalloproteinase activities, often using similar strategies as used in prodrug design [145]. For instance, near-infrared fluorophores joined by peptide protease substrates become de-quenched upon cleavage [146]. Protease cleavage can also lead to aggregation and signal enhancement of magnetic nanoparticles for MRI [147], and ${ }^{18} \mathrm{~F}$ PET tracers have been developed based on tight binding protease inhibitors [148]. scRNAseq and imaging data underline the heterogeneity of protease activities at sites of disease across patients, particularly in solid cancers, due to variability in both the level of immune-cell infiltration, and in the regulated expression and activity of proteases in the cells that are present [37]. This variability motivates companion diagnostic or theranostic approaches to identify patients likely to respond to protease-sensitive prodrugs or protease inhibitors.
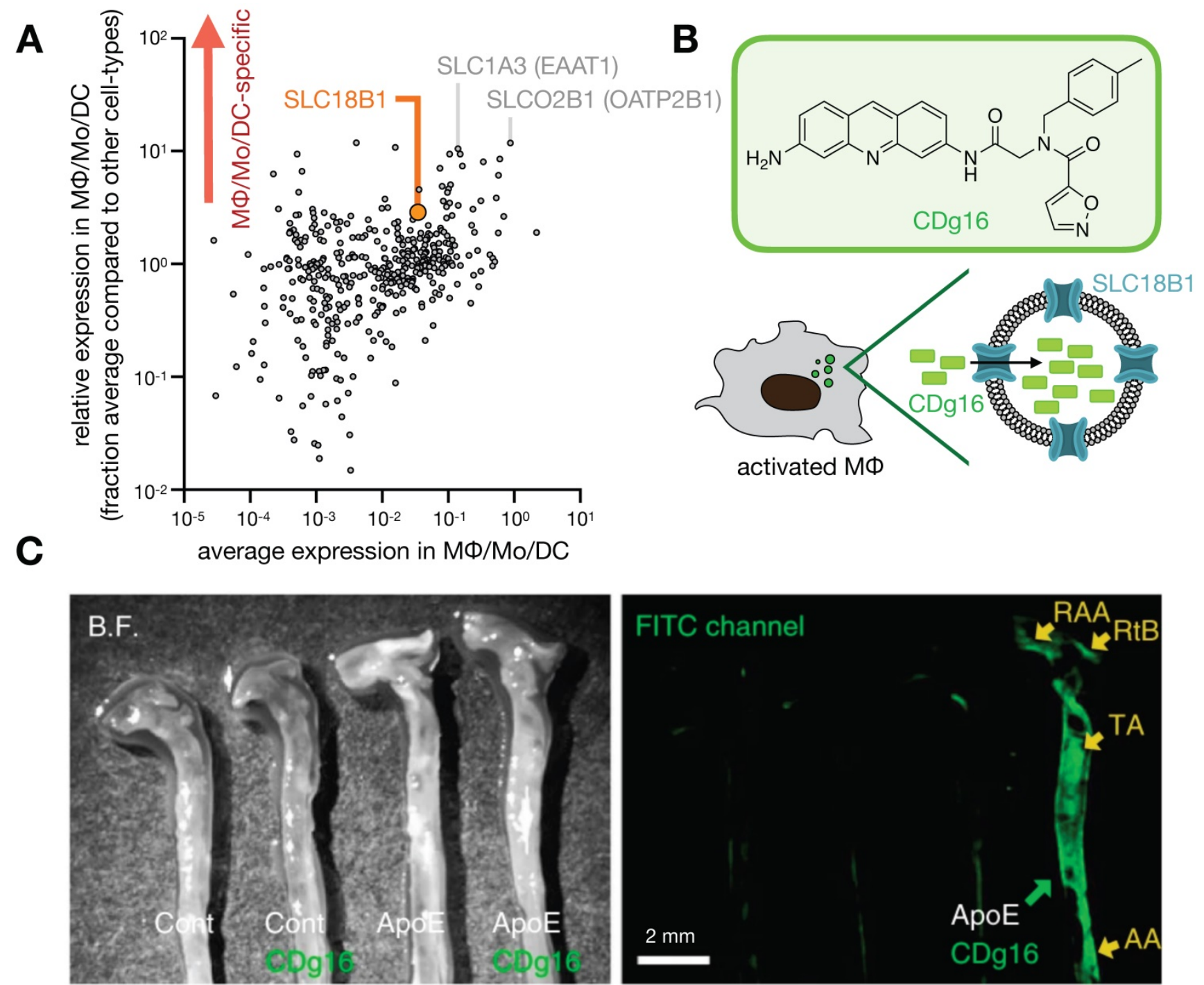

Figure 7. Probing solute carrier family proteins. A) As in Fig. 1, scRNAseq was pooled from 7 patients with lung cancer, and expression of 406 solute carrier family (SLC) genes were plotted as a function of average expression (x-axis) and selectivity of expression within the lung ( $y$-axis), among cells in the MФ/Mo/DC cluster. From GSE127465 and SPRING analysis in [37]. B) The fluorescent probe CDg16 was identified in a high-throughput screen as selectively accumulating in activated M $\Phi$, and CRISPR screening revealed SLC18B1-mediated uptake [142]. C) CDg16 was used to image MФ-rich plaques in the aortas of atherosclerotic ApoE-knockout mice. Excised vessels are annotated with the root of the aorta arch (RAA), the right brachiocephalic artery (RtB), the thoracic aorta (TA), and the abdominal aorta (AA). C, adapted with permission from [142], copyright 2019. 


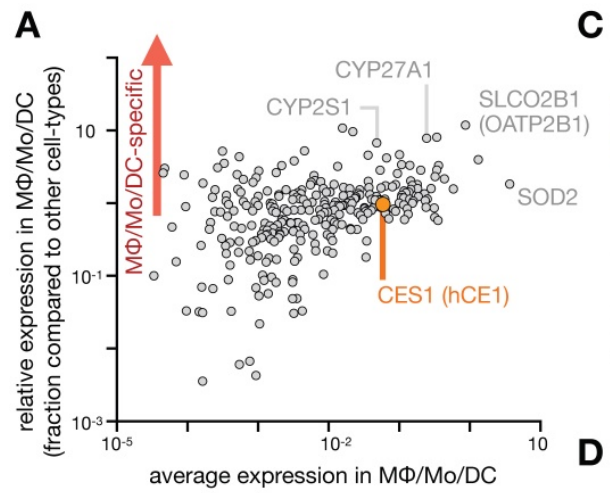

B

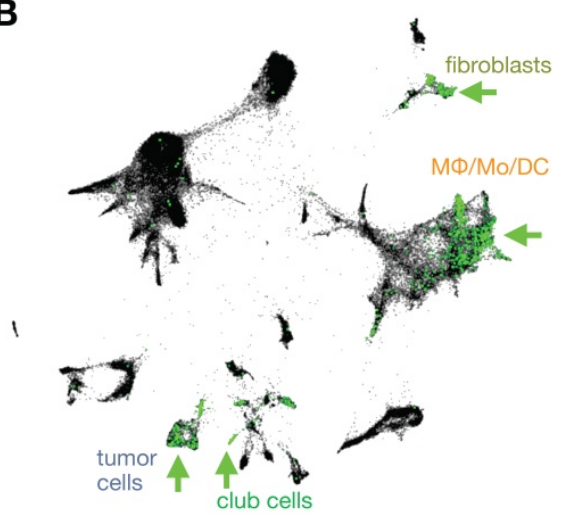

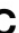
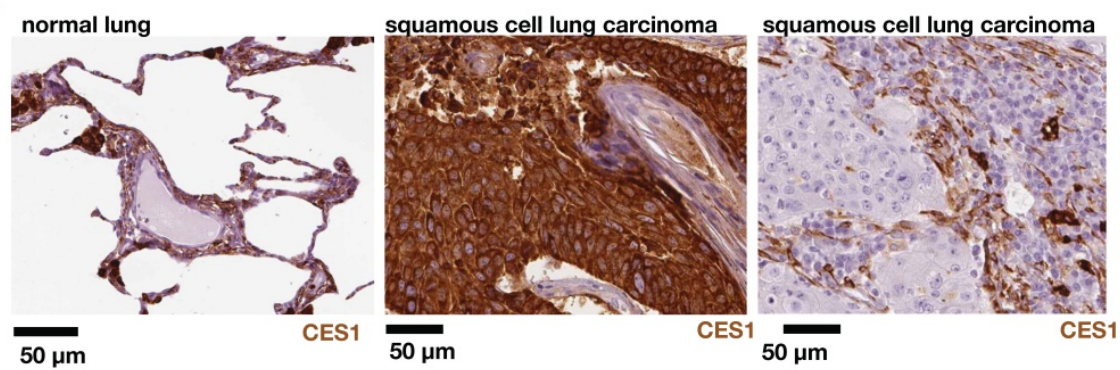

activation

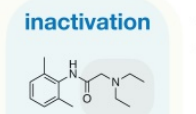

E

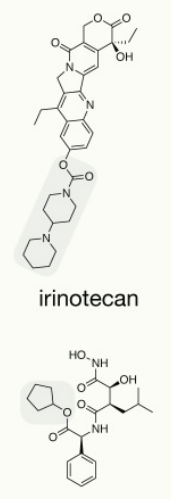

tosedostat
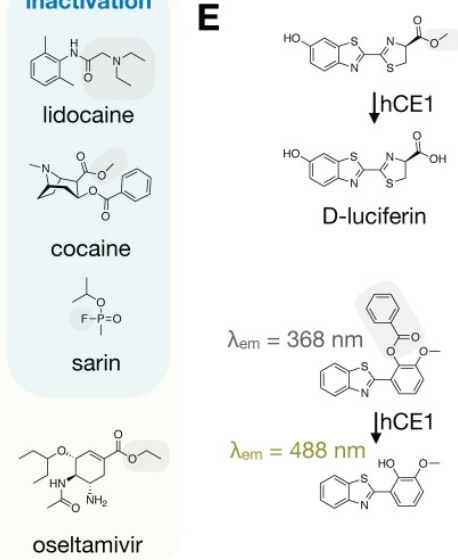

\hCE1

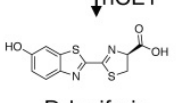

D-luciferin
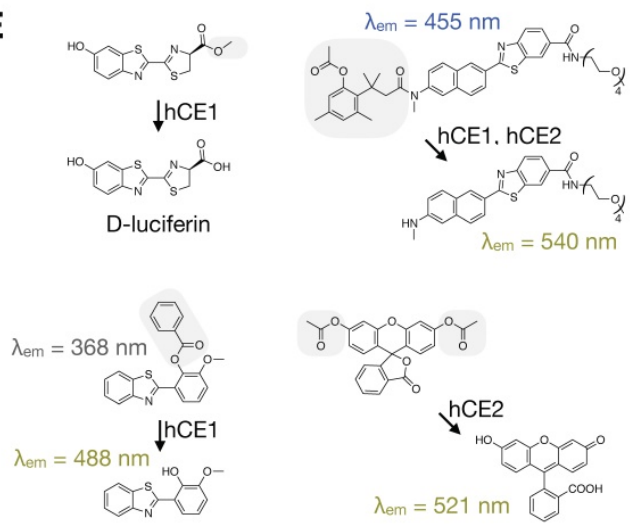

Figure 8. MФ expression and imaging of ADME-relevant enzymes and transporters. A) As in Fig. 1, single-cell RNAseq was pooled from 7 patients with lung cancer, and expression of 288 high-priority genes related to drug PK (www.PharmaADME.org) were plotted as a function of average expression (x-axis) and selectivity of expression within the lung (y-axis), among cells in the MФ/Mo/DC cluster. From GSE127465 and SPRING analysis in [37]. B) Corresponding to A and Fig. 1, data were clustered according to cell-type, and expression of CES1 (hCE1) is shown in green. Arrows highlight high-expressing populations. C) Immunohistochemistry of CES1 in biopsied healthy and malignant lung tissue, showing representative examples of staining consistent with high expression in alveolar MФ (left), high tumor-cell expression (middle), and high phagocyte or stromal expression (right). From the Human Protein Atlas v19.3 [195]. D) Example CES1-activatable prodrugs, and CES1-neutralized substances, which may be metabolized by phagocytes in the lung. Gray boxes mark site of carboxylesterase cleavage. E) Probes have been developed to report carboxylesterase activity, with relative CES1 versus CES2 specificity noted. CES-mediated cleavage yields a functional bioluminescence substrate (top left [196]), creates a red-shift in fluorescence following single-photon (bottom left [197]) or two-photon fluorescence excitation (top right [198]), and turns on fluorescence, as with fluorescein diacetate which is used with purified enzyme [199] or as a readout of cell viability (bottom right).

CYP family enzymes. Some metabolic enzymes including cytochrome P450 oxidases are expressed in phagocytes, although they are more associated with processing endogenous lipid and sterol inflammatory mediators rather than xenobiotics. The cytochrome P450 oxidase CYP27A1, also known as sterol 27-hydroxylase, is expressed in $M \Phi$ and generates 27-hydroxycholesterol. This product is a selective estrogen receptor modulator and liver $\mathrm{X}$ receptor agonist, has been implicated in linking hypercholesterolemia with breast cancer development [149], and has consequently been considered as a adjuvant drug target in breast cancer. Cytochrome P450 2S1 (CYP2S1) is also expressed in $M \Phi$, exhibits epoxygenase activity, and acts on fatty acids, prostaglandins, and vitamin D3 [150].

Carboxylesterase 1. Carboxylesterase 1 (CES1, also known as human carboxylesterase 1, hCE1) can be highly expressed in phagocytes such as $M \Phi$, and in the past CES1 has been referred to as monocyte esterase. CES1 is not specific to phagocytes, and the majority of carboxylesterase processing of xenobiotics occurs in the liver (by CES1) and intestine (by CES2)
(Fig. 9). Nonetheless, in tissues such as the lung, phagocytes like alveolar M $\Phi$ express CES1 and can metabolize inhaled substances before they reach the liver [151]. Relevant CES1 substrates include narcotics and organophosphate toxins such as sarin and VX gases.

CES1 can also activate prodrugs, including steroids, chemotherapeutics, and anti-virals like oseltamivir (marketed as Tamiflu) (Fig. 8d-e) [152]. CES1 and CES2 have many shared substrates, but some prodrugs such as irinotecan show preferential cleavage by CES2, which is not typically expressed in phagocytes [153]. In other cases, prodrugs can be encapsulated in long-circulating liposomes or other nanoparticles, which can be efficiently taken up at target sites of phagocyte accumulation before being metabolized in the liver. Liposomal irinotecan (Onivyde) is thought to rely on local uptake and prodrug activation by TAM, in part through MФ-expressed CES1 [9]. Onivyde response in patients was correlated with the ability of tumors to accumulate ferumoxytol, supporting the model that $\mathrm{M} \Phi$ contribute to delivery and activation of liposomal 
irinotecan in tumors [9]. Esterase-activated steroid prodrugs have also been developed for encapsulation within lipid nanoparticles, in one example to mitigate unwanted immunogenic effects of siRNA delivery
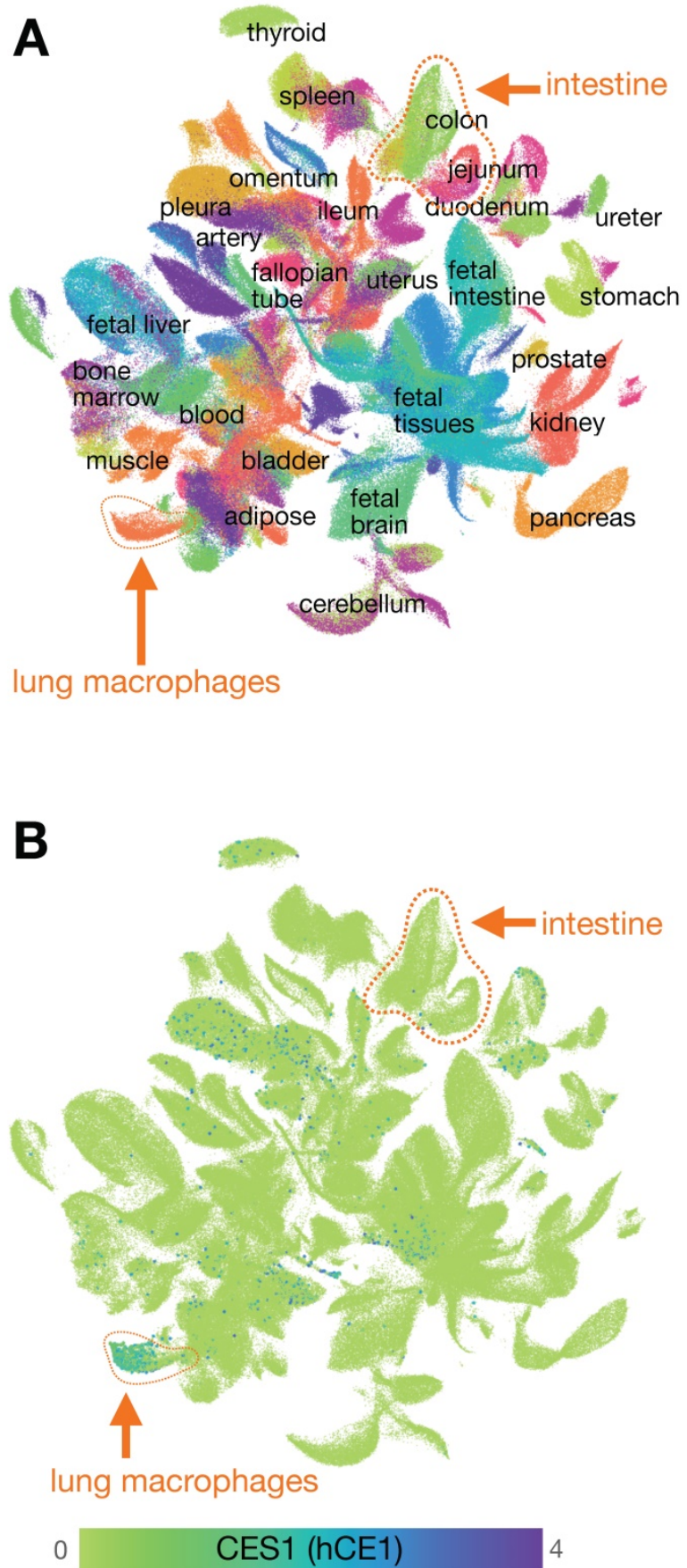

[154]. The steroid ciclesonide is nebulized as a treatment for asthma and allergic rhinitis, and may be activated directly in the lung by CES-expressing epithelium and phagocytes [155].
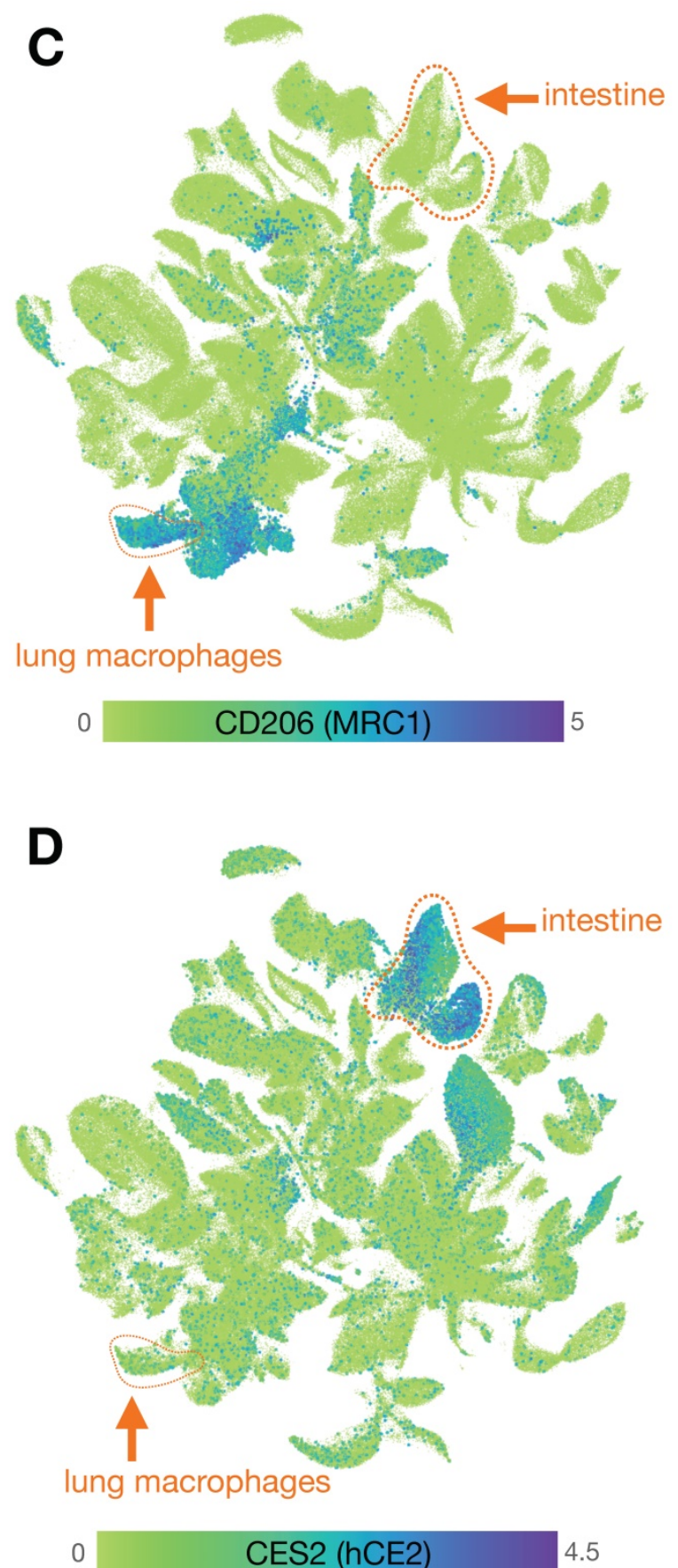

Figure 9. Mapping carboxylesterase expression using the Human Cell Landscape. A) Clustering of scRNAseq data from the human cell landscape project [29] shows $>700,000$ individual cells colored according to their tissue of origin. Epithelial cells from the intestine (primarily EpCAM+ cells including from the colon, rectum, jejunum, and duodenum) and myeloid cells from the lung (primarily CD68+ CD206+ cells, referred to here as lung MФ) are highlighted. B) CESI is found expressed in the cluster of cells that includes high levels of lung MФ, and is relatively absent in intestinal epithelium. C) Expression of CD206 is high in the cluster of CESI+ cells identified as lung MФ, but is not restricted to that population. D) CES2 is highly expressed in the intestinal epithelium compared to lung M $\Phi$. See CellXGene and https://db.cngb.org/HCL/ for software to generate plots, described in [29]. 
Even orally administered prodrugs may be partly activated by phagocytes at sites of disease. For instance, animal models have shown higher active metabolite concentrations of the CES1 substrate oseltamivir in the lung than in circulation [156], suggesting further metabolic activation in tissue, despite most being systemically activated. Systemically administered prodrugs have been developed to mitigate exposure of active compound outside of targeted cell populations, for instance with the CES1 substrate and aminopeptidase inhibitor tosedostat, which has been developed for the treatment of myeloid leukemias. Tosedostat is one of a class of drugs designed with an "esterase sensitive motif" approach that in principle targets CES1-expressing monocytes, $\mathrm{M} \Phi$, and leukemias that arise from phagocyte myeloid precursors. Unfortunately, studies with tosedostat revealed that drug resistance emerged as leukemia cells adapted to lose expression of CES1 [157].

Achieving local CES1-mediated prodrug activation requires balancing on-target activation with metabolization by other esterases in circulation such as serum paraoxonase/arylesterase 1 (PON1), which is also known as A esterase. In fact, PON1 activity has been used to design so-called "soft drugs" that achieve local activity by becoming metabolized to inactive forms upon reaching circulation [158]. Complicating these efforts, carboxylesterases are distinct between mice and humans, and consist of 20 and 6 members, respectively. Mouse carboxylesterases are not highly expressed in $M \Phi[37$, 159]. In contrast, mouse and rat carboxylesterase Ces1c is present at high levels in plasma and has been noted to degrade antibody-drug conjugates faster than the rate seen in humans, motivating use of Ces1c $\mathrm{c}^{-/-}$mice to better model PK of antibody drug conjugates [160]. The same approach has been applied for the antiviral remdesivir, which shows efficacy against the SARS-CoV-2 coronavirus.

\section{Phagocytes as drug depots}

Nanoparticles and antibodies have both been used to more safely deliver toxic drugs to target cell populations in multiple diseases, for instance with PEGylated liposomal doxorubicin (Doxil) used to treat ovarian cancer, Kaposi's Sarcoma, and multiple myeloma, and the ADC ado-trastuzumab emtansine (Kadcyla) used to treat HER2+ metastatic breast cancer. ADCs and drug-loaded nanotherapies in oncology can have high off-target accumulation in phagocytes [81, 161, 162]. The functional consequence of this uptake depends on the drug formulation and the biology of the phagocytes in which they accumulate. TAM can serve as drug depots that redistribute cytotoxic payload to surrounding tumor cells after they have taken up the ADC or nanoparticle delivery vehicle, leading to desired bystander killing $[7,15,163]$. In follow-up, M $\Phi$ depletion decreased intratumoral accumulation of therapeutic nanoparticles and resulted in tumor growth [7]. M $\Phi$ depletion using clodronate liposomes similarly reduced the effectiveness of tumor-targeted ADC, as did the use of ADC mutants with attenuated $F_{C}$ R1 binding [163]. TAM-mediated bystander killing has also been shown in mouse models using TAM-targeted aptamers that indirectly deliver the chemotherapy doxorubicin to tumor cells [164]. In addition to the cytotoxic payload, TAM can release nanoparticles themselves after initial uptake, thus promoting subsequent delivery to neighboring tumor cells [165]. The uptake of nanoparticles by phagocytes has also been used to affect neighboring cells by stimulating phagocyte production of cytokines [93], chemoattractants [166-167], or vaccine-targeted antigens [168]. In other cases, phagocyte uptake may lead to unwanted drug sequestration or systemic clearance, and studies have shown how depleting $\mathrm{M} \Phi$ [162], or saturating their ability to take up materials such as nanoparticles [169-171], can improve on-target delivery. MФ-targeting agents such as the dextran-based nanoparticles Macrin and ferumoxytol, therefore, have potential utility as companion diagnostics for agents that are affected by drug depot, myeloid-reprogramming, or sequestration effects [15, $21,169]$.

\section{Exploiting myeloid-shaped tissue environments for drug delivery}

Drug pharmacokinetics are influenced by abnormal vascular structures and permeability, interstitial fluid pressure change, lymphatic function, and extracellular matrix composition. These issues are particularly acute in solid cancers and with nanoparticles, which are thought to passively accumulate in some solid tumors via the EPR effect [4, $5,172]$. Myeloid cells play central roles in shaping the vasculature, extracellular matrix, and overall EPR effect of tissues. For instance, perivascular TAM and neutrophils can produce growth factors including vascular endothelial growth factor (VEGF) to promote angiogenesis and metastasis in solid tumors [173], and this also can promote local bursts of vessel permeability and drug penetration into tissue $[8,174]$. As an example of how this may be exploited to enhance drug delivery in tumors, low-dose radiation was used to enrich solid tumors for $М \Phi$ content, which led to altered tumor vascularization and improved nanotherapy delivery in a M $\Phi$-dependent manner [8, 170]. Targeted kinase inhibition, 
immunogenic chemotherapy, and immune checkpoint blockade have all been shown to stimulate myeloid infiltration and subsequent nanoparticle accumulation in tumors $[15,175,176]$. In the case of targeted mitogen activated protein kinase (MAPK) extracellular related kinase (ERK) inhibition in Braf ${ }^{\mathrm{V} 600 \mathrm{E}}$ cancers, inhibition of the MAPK/ERK pathway using a clinical MEK1/2 inhibitor enriched xenografts for TAM content, stimulated VEGF and growth factor production in $M \Phi$, stimulated $M \Phi$ to more avidly accumulate nanoparticles, and therefore led to greater nanoparticle uptake in treated tumors (Fig. 10) [11]. Analysis of these tumor cell populations by scRNAseq elucidated the complex ligand-receptor communication that occurs between tumor cells and $M \Phi$, offering new avenues for therapeutic intervention.

\section{Conclusions and Future Directions}

Although this review outlines examples of $M \Phi$ imaging and phagocyte involvement in drug distribution and inactivation, the ability to intervene in these mechanisms to impact patient outcomes remains limited. One of the challenges remains the scope required to completely characterize the contribution of each immune cell type, while also maintaining the capacity to serially-sample and track the "kinetics" aspect of drug PK. In terms of multiplexing breadth at single-cell levels, scRNAseq is unmatched in the information provided: gene expression profiles can be used to subset cells, identify unique surface markers, and trace lineages. This information complements molecular imaging, as the unique cellular markers can be used to map cell subsets across time and space in a minimally-invasive manner, including across other types of immune cells such as T-cells [177-181]. When used in this way a single gene, a signature, or even a cell type can become a biomarker to guide drug discovery efforts. As therapeutic modalities become increasingly complex in the age of cell and gene therapy, small molecule cocktails, and bi-specific engagers, the shift to more complex and comprehensive biomarkers may complement theranostic imaging of these agents $[177,178,181]$. Multiplexed measurements like the recently approved FoundationOne CDX companion diagnostic for MET inhibition in non-small cell lung cancer (Foundation Medicine, Inc., Cambridge, MA) or the NanoString Prosigna Breast Cancer gene signature assay (NanoString Technologies, Seattle, WA) signal that transcriptomic signatures may someday be as commonplace as the longitudinal multidimensional diagnostic information provided by traditional radiographic medicine. Despite this promising future, hurdles remain.

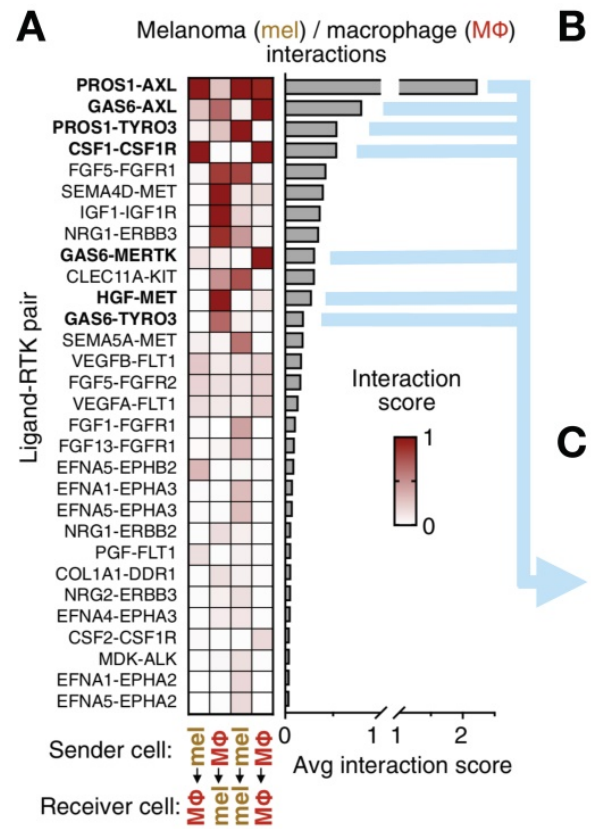

B
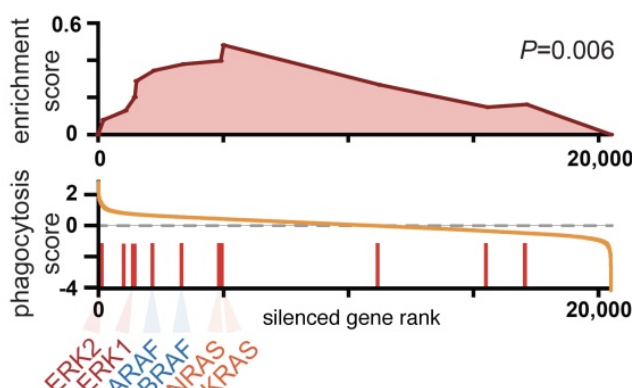

C

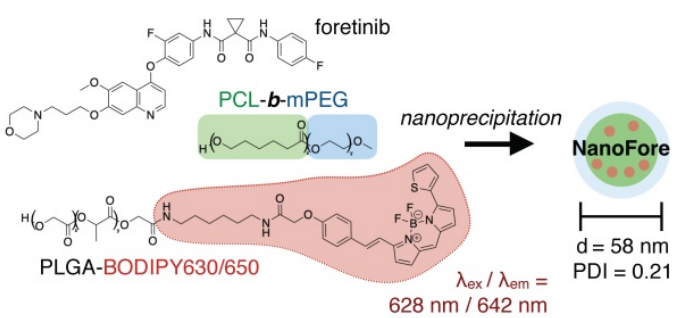

D

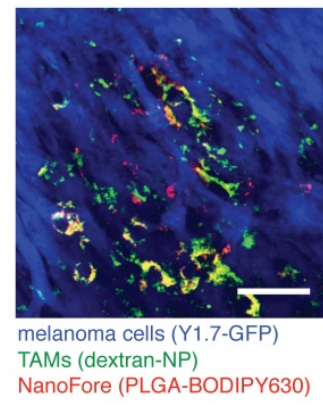

E

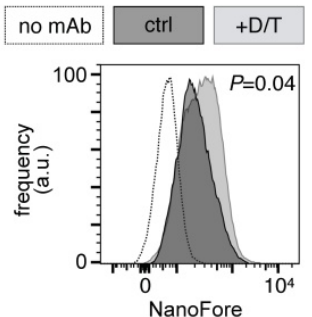

Figure 10. Clinical kinase inhibitors influence tumor associated $M \Phi$ to improve nanotherapy delivery. A) scRNAseq from BRAF-mutant melanoma biopsies tabulated ligand-receptor communication between malignant melanoma cells ("mel") and MФ across $>1100$ known ligand-receptor pairs; top receptor tyrosine kinase (RTK) pathways are shown. B) Gene set enrichment analysis of a genomic CRISPR screen shows that genetic silencing of MAPK/ERK pathway components - including RAS, RAF, and ERK proteins - leads to enhanced uptake of nanoparticles in MФ. Genes were ranked according to the effect their CRISPR-mediated silencing had on nanoparticle uptake. MAPK/ERK components were enriched in increasing uptake. C) A nanoformulation encapsulates the multi-kinase inhibitor foretinib into micelles composed of poly( $\varepsilon$-caprolactone)-block-methoxy poly(ethylene glycol) (PCL-b-mPEG) and poly(lactic-co-glycolic) acid (PLGA), producing "NanoFore." Key drug targets are boldfaced in A. D) NanoFore accumulates in tumor associated MФ within melanoma allografts, as measured by confocal microscopy. Macrin (dextran-NP; see Fig. 2) was used to label MФ. Scale bar, $50 \mu \mathrm{m}$. E-F) As predicted by the CRISPR screen in B, inhibition of MAPK/ERK activity with clinically-used BRAF inhibitor (dabrafenib) and MEK1/2 inhibitor (trametinib) " $D / T$ " led to enrichment of $M \Phi$ in tumors (see ref. [1 1 ]), and a roughly $2 x$ increase in NanoFore uptake in M $\Phi$ on a per-cell basis, as measured by flow cytometry. For all, adapted with permission from [11], copyright 2020, and with data from [200]. 
Tissue heterogeneity makes sampling for transcriptomic analysis particularly difficult. Appreciation for heterogeneity is reflected in recent efforts to integrate spatial coordinates into single cell RNAseq and probe hybridization methods [182-184]. Photoactivatable probes have even been used to guide the precise sampling of tissue for single cell analysis [185]. T-cell receptor (TCR) sequencing is now a routine method that tracks the expansion of $\mathrm{T}$ cell clones over time [186, 187], and methods to monitor B cell diversity have been made commercially-available [188]. Without a clonal marker like the TCR/BCR, M $\Phi$ and neutrophil expansion and turnover are still measured primarily with fluorophores detected by microscopy or flow cytometry [189]. New methods to barcode monocytes for lineage tracing are currently in development [190]. The integration of pooled CRISPR screens with scRNAseq may finally bring myeloid cells into the scope of functional genomics, permitting the testing of the influence of thousands of genes in parallel on monocyte differentiation and niche formation [31, 191].

Transcriptomic analysis has underlined that immune cells aren't held in static states, but are ever-changing in response to environmental cues. The artifacts introduced by tissue dissociation and cell/nuclei prep for transcriptional analysis [192] may be better understood and partially alleviated with complementary in situ imaging for cell stress hallmarks or population loss. Another way to counteract the tightly-regulated production and degradation of many inflammatory mRNAs is to focus instead on the epigenetic level. Chromosomal accessibility measured by ATACseq has provided a clearer picture of the differences between reversible and permanently-dysfunctional lymphocytes [193]. Despite these insights, transcriptomics still provides just a snapshot in time, and the requirement for tissue sampling is greatly limited by the accessibility of clinically-relevant diseased tissues. Molecular imaging contextualizes the often transient transcriptomic information encoded in multiplexed single cell approaches. As this information is integrated, the hope is that new treatment biomarkers, resistance mechanisms, and cell-specific drug targets will be identified.

Given the broad involvement of macrophages in human disease and treatment response, particularly in inflammation, infection, and cancer, macrophagecentered diagnostics represent a practical application for transcriptomic and spatial technologies. One clear translational area lies in the development of prognostic or predictive biomarkers. Multiple clinical studies have correlated imaging and/or other readouts of macrophage behavior with disease progression, response to macrophage-influenced therapies such as liposomal irinotecan in advanced solid cancers [9], and response to PD1-targeted immune checkpoint blockade for instance in melanoma [10], as described above. Aside from abundance, altered TAM distribution in the tumor and neighboring tissue can be predictive of treatment response [201]. Macrophage shape [94; 202] and transcriptional phenotype [203] also represent potential pathological parameters that can inform patient stratification or serve as companion markers of surrogate endpoints in clinical trials. Practical, logistic, and economic considerations all are challenges in successfully moving such applications from research into practice.

\section{Abbreviations}

ADC: antibody drug conjugate; ADCC: antibody dependent cell-mediated cytotoxicity; BCR: b-cell receptor; DC: dendritic cell; EPR: enhanced permeability and retention; scRNAseq: single-cell RNA sequencing; $M \Phi$ : macrophage; mAb: monoclonal antibody; MAPK: mitogen activated protein kinase; MRI: magnetic resonance imaging; NK: natural killer; PET/CT: positron emission tomograph/X-ray computed tomography; PK: pharmacokinetic; TAM: tumor associated macrophage; TCR: $t$-cell receptor.

\section{Acknowledgments}

This work was supported in part by NIH/NCI grants R00CA207744, U01CA206997, and R01CA206890, the American Thyroid Association, and the Thyroid Cancer Survivors' Association, Inc. R.L. was supported in part by NIH/NCI T32CA079443 and a Tosteson Fellowship (Massachusetts General Hospital). We are grateful for the scientific and editorial leadership of Dr. Moritz Kircher, who originally invited this review. His recent passing is an enormous loss for the community, and he will be deeply missed.

\section{Competing Interests}

The authors have declared that no competing interest exists.

\section{References}

[1] Pollard JW. Trophic Macrophages in Development and Disease. Nat Rev Immunol. 2009; 9: 259-270.

[2] Ngambenjawong C, Gustafson HH, Pun SH. Progress in Tumor-Associated Macrophage (TAM)-Targeted Therapeutics. Adv Drug Deliv Rev. 2017; 114: 206-221.

[3] Drummond DC, Noble CO, Guo Z, Hong K, Park JW, Kirpotin DB et al. Development of a Highly Active Nanoliposomal Irinotecan Using a Novel Intraliposomal Stabilization Strategy. Cancer Res. 2006; 66: 3271-3277.

[4] Maeda H, Wu J, Sawa T, Matsumura Y, Hori K. Tumor Vascular Permeability and the EPR Effect in Macromolecular Therapeutics: A Review. J Control Release. 2000; 65: 271-284. 
[5] Shi J, Kantoff PW, Wooster R, Farokhzad OC. Cancer Nanomedicine: Progress, Challenges and Opportunities. Nat Rev Cancer. 2017; 17: 20-37.

[6] Wilhelm S, Tavares AJ, Dai Q, Ohta S, Audet J, Dvorak HF et al. Analysis of Nanoparticle Delivery to Tumours. Nat Rev Mater. 2016; 1: 16014.

[7] Miller MA, Zheng YR, Gadde S, Pfirschke C, Zope H, Engblom C et al. Tumour-Associated Macrophages Act as a Slow-Release Reservoir of Nano-Therapeutic Pt(IV) Pro-Drug. Nat Commun. 2015; 6: 8692.

[8] Miller MA, Chandra R, Cuccarese MF, Pfirschke C, Engblom C, Stapleton S et al. Radiation Therapy Primes Tumors for Nanotherapeutic Delivery Via Macrophage-Mediated Vascular Bursts. Sci Transl Med. 2017; 9: eaal0225.

[9] Ramanathan RK, Korn RL, Raghunand N, Sachdev JC, Newbold RG, Jameson $\mathrm{G}$ et al. Correlation Between Ferumoxytol Uptake in Tumor Lesions By MRI and Response to Nanoliposomal Irinotecan in Patients With Advanced Solid Tumors: A Pilot Study. Clin Cancer Res. 2017; 23: 3638-3648.

[10] Riaz N, Havel JJ, Makarov V, Desrichard A, Urba WJ, Sims JS et al. Tumor and Microenvironment Evolution During Immunotherapy With Nivolumab. Cell. 2017; 171: 934-949.

[11] Wang SJ, Li R, Ng TSC, Luthria G, Oudin MJ, Prytyskach M et al. Efficient Blockade of Locally Reciprocated Tumor-Macrophage Signaling Using a TAM-Avid Nanotherapy. Sci Adv. 2020; 6: eaaz8521.

[12] Patel U, Rajasingh S, Samanta S, Cao T, Dawn B, Rajasingh J et al. Macrophage Polarization in Response to Epigenetic Modifiers During Infection and Inflammation. Drug Discov Today. 2017; 22: 186-193.

[13] Gaglia JL, Harisinghani M, Aganj I, Wojtkiewicz GR, Hedgire S, Benoist C et al. Noninvasive Mapping of Pancreatic Inflammation in Recent-Onset Type-1 Diabetes Patients. Proc Natl Acad Sci U S A. 2015; 112: 2139-2144.

[14] Khurana A, Chapelin F, Xu H, Acevedo JR, Molinolo A, et al. Visualization of Macrophage Recruitment in Head and Neck Carcinoma Model Using fluorine-19 Magnetic Resonance Imaging. Magn Reson Med. 2018; 79: 1972-1980.

[15] Kim HY, Li R, Ng TSC, Courties G, Rodell CB, Prytyskach $\mathrm{M}$ et al Quantitative Imaging of Tumor-Associated Macrophages and Their Response to Therapy Using ${ }^{64} \mathrm{Cu}$-Labeled Macrin. ACS Nano. 2018; 12: 12015-12029.

[16] Kirschbaum K, Sonner JK, Zeller MW, Deumelandt K, Bode J, Sharma R et al. In Vivo Nanoparticle Imaging of Innate Immune Cells Can Serve as a Marker of Disease Severity in a Model of Multiple Sclerosis. Proc Natl Acad Sci U S A. 2016; 113: 13227-13232.

[17] Mohanty S, Yerneni K, Theruvath JL, Graef CM, Nejadnik H, Lenkov O et al. Nanoparticle Enhanced MRI Can Monitor Macrophage Response to Cd47 MAb Immunotherapy in Osteosarcoma. Cell Death Dis. 2019; 10: 36.

[18] Perez-Medina C, Tang J, Abdel-Atti D, Hogstad B, Merad M, Fisher EA et al. PET Imaging of Tumor-Associated Macrophages With ${ }^{89} \mathrm{Zr}$-Labeled High-Density Lipoprotein Nanoparticles. J Nucl Med. 2015; 56: 1272-1277.

[19] Miller MA, Arlauckas S, Weissleder R. Prediction of Anti-Cancer Nanotherapy Efficacy By Imaging. Nanotheranostics. 2017; 1: 296-312.

[20] Miller MA, Gadde S, Pfirschke C, Engblom C, Sprachman MM, Kohler RH et al. Predicting Therapeutic Nanomedicine Efficacy Using a Companion Magnetic Resonance Imaging Nanoparticle. Sci Transl Med. 2015; 7: 314ra183.

[21] Iv M, Samghabadi P, Holdsworth S, Gentles A, Rezaii P, et al. Quantification of Macrophages in High-Grade Gliomas by Using Ferumoxytol-enhanced MRI: A Pilot Study. Radiology. 2019; 290: 198-206.

[22] Aghighi M, Theruvath AJ, Pareek A, Pisani LL, Alford R, et al. Magnetic Resonance Imaging of Tumor-Associated Macrophages: Clinical Translation. Clin Canc Res. 2018; 24: 4110-4118.

[23] Fernández A, Vendrell M. Smart Fluorescent Probes for Imaging Macrophage Activity. Chem Soc Rev. 2016; 45: 1182-1196.

[24] Foss CA, Sanchez-Bautista J, Jain SK. Imaging Macrophage-Associated Inflammation. Semin Nucl Med. 2018; 48: 242-245.

[25] Serkova NJ. Nanoparticle-Based Magnetic Resonance Imaging on Tumor-Associated Macrophages and Inflammation. Front Immunol. 2017; 8: 590.

[26] Patel SK, Janjic JM. Macrophage Targeted Theranostics as Personalized Nanomedicine Strategies for Inflammatory Diseases. Theranostics. 2015; 5: 150-172.

[27] Korangath P, Barnett JD, Sharma A, Henderson ET, Stewart J, Yu SH et al. Nanoparticle Interactions With Immune Cells Dominate Tumor Retention and Induce T Cell-Mediated Tumor Suppression in Models of Breast Cancer. Sci Adv. 2020; 6: eaay1601.

[28] Tirosh I, Izar B, Prakadan SM, Wadsworth MH, Treacy D, Trombetta JJ et al. Dissecting the Multicellular Ecosystem of Metastatic Melanoma By Single-Cell RNA-Seq. Science. 2016; 352: 189-196.

[29] Han X, Zhou Z, Fei L, Sun H, Wang R, Chen Y et al. Construction of a Human Cell Landscape At Single-Cell Level. Nature. 2020; 581: 303-309.

[30] Peterson VM, Zhang KX, Kumar N, Wong J, Li L, Wilson DC et al. Multiplexed Quantification of Proteins and Transcripts in Single Cells. Nat Biotechnol. 2017; 35: 936-939.

[31] Dixit A, Parnas O, Li B, Chen J, Fulco CP, Jerby-Arnon L et al. Perturb-Seq: Dissecting Molecular Circuits With Scalable Single-Cell RNA Profiling of Pooled Genetic Screens. Cell. 2016; 167: 1853-1866.e17.

[32] Edsgärd D, Johnsson P, Sandberg R. Identification of Spatial Expression Trends in Single-Cell Gene Expression Data. Nat Methods. 2018; 15: 339-342.

[33] Ha MK, Kwon SJ, Choi JS, Nguyen NT, Song J, Lee Y et al. Mass Cytometry and Single-Cell RNA-Seq Profiling of the Heterogeneity in Human Peripheral Blood Mononuclear Cells Interacting With Silver Nanoparticles. Small. 2020; 16: e1907674.
[34] Chen H, Ye F, Guo G. Revolutionizing Immunology With Single-Cell RNA Sequencing. Cell Mol Immunol. 2019; 16: 242-249.

[35] MacParland SA, Liu JC, Ma XZ, Innes BT, Bartczak AM, Gage BK et al. Single Cell RNA Sequencing of Human Liver Reveals Distinct Intrahepatic Macrophage Populations. Nat Commun. 2018; 9: 4383.

[36] Papalexi E, Satija R. Single-Cell RNA Sequencing to Explore Immune Cell Heterogeneity. Nat Rev Immunol. 2018; 18: 35-45.

[37] Zilionis R, Engblom C, Pfirschke C, Savova V, Zemmour D, Saatcioglu HD et al. Single-Cell Transcriptomics of Human and Mouse Lung Cancers Reveals Conserved Myeloid Populations Across Individuals and Species. Immunity. 2019; 50: 1317-1334.e10.

[38] Celus W, Di Conza G, Oliveira AI, Ehling M, Costa BM, Wenes M et al. Loss of Caveolin-1 in Metastasis-Associated Macrophages Drives Lung Metastatic Growth Through Increased Angiogenesis. Cell Rep. 2017; 21: 2842-2854.

[39] Musallam KM, Taher AT. Iron Deficiency Beyond Erythropoiesis: Should We be Concerned. Curr Med Res Opin. 2018; 34: 81-93.

[40] Graversen JH, Svendsen P, Dagnæs-Hansen F, Dal J, Anton G, Etzerodt A et al. Targeting the Hemoglobin Scavenger Receptor CD163 in Macrophages Highly Increases the Anti-Inflammatory Potency of Dexamethasone. Mol Ther. 2012; 20: $1550-1558$

[41] Rafique A, Etzerodt A, Graversen JH, Moestrup SK, Dagnæs-Hansen F, Møller HJ et al. Targeted Lipid Nanoparticle Delivery of Calcitriol to Human Monocyte-Derived Macrophages in Vitro and in Vivo: Investigation of the Anti-Inflammatory Effects of Calcitriol. Int J Nanomedicine. 2019; 14: 2829-2846.

[42] Sukhbaatar N, Weichhart T. Iron Regulation: Macrophages in Control. Pharmaceuticals (Basel). 2018; 11: 137

[43] Kim SS, Rait A, Garrido-Sanabria ER, Pirollo KF, Harford JB, Chang EH et al. Nanotherapeutics for Gene Modulation That Prevents Apoptosis in the Brain and Fatal Neuroinflammation. Mol Ther. 2018; 26: 84-94.

[44] Jaynes JM, Sable R, Ronzetti M, Bautista W, Knotts Z, Abisoye-Ogunniyan A et al. Mannose Receptor (CD206) Activation in Tumor-Associated Macrophages Enhances Adaptive and Innate Antitumor Immune Responses. Sci Transl Med. 2020; 12: eaax6337.

[45] Xiao T. Innate Immune Recognition of Nucleic Acids. Immunol Res. 2009; 43: 98-108.

[46] Wang G, Serkova NJ, Groman EV, Scheinman RI, Simberg D. Feraheme (Ferumoxytol) is Recognized By Proinflammatory and Anti-Inflammatory Macrophages Via Scavenger Receptor Type AI/II. Mol Pharm. 2019; 16: $4274-4281$

[47] Xue J, Schmidt SV, Sander J, Draffehn A, Krebs W, Quester I et al. Transcriptome-Based Network Analysis Reveals a Spectrum Model of Human Macrophage Activation. Immunity. 2014; 40: 274-288.

[48] Crane MJ, Daley JM, van Houtte O, Brancato SK, Henry WL, Albina JE et al. The Monocyte to Macrophage Transition in the Murine Sterile Wound. PLoS One. 2014; 9: e86660.

[49] Noy R, Pollard JW. Tumor-Associated Macrophages: From Mechanisms to Therapy. Immunity. 2014; 41: 49-61.

[50] Zhang C, Yu X, Gao L, Zhao Y, Lai J, Lu D et al. Noninvasive Imaging of CD206-Positive M2 Macrophages as an Early Biomarker for Post-Chemotherapy Tumor Relapse and Lymph Node Metastasis. Theranostics. 2017; 7: 4276-4288.

[51] Reese TA, Liang HE, Tager AM, Luster AD, Van Rooijen N, Voehringer D et al. Chitin Induces Accumulation in Tissue of Innate Immune Cells Associated With Allergy. Nature. 2007; 447: 92-96.

[52] Allavena P, Chieppa M, Bianchi G, Solinas G, Fabbri M, Laskarin G et al. Engagement of the Mannose Receptor By Tumoral Mucins Activates an Immune Suppressive Phenotype in Human Tumor-Associated Macrophages. Clin Dev Immunol. 2010; 2010: 547179

[53] Hansson GK, Libby P. The Immune Response in Atherosclerosis: A Double-Edged Sword. Nat Rev Immunol. 2006; 6: 508-519.

[54] Petersen LK, York AW, Lewis DR, Ahuja S, Uhrich KE, Prud'homme RK et al. Amphiphilic Nanoparticles Repress Macrophage Atherogenesis: Novel Core/shell Designs for Scavenger Receptor Targeting and Down-Regulation. Mol Pharm. 2014; 11: 2815-2824.

[55] Lewis DR, Petersen LK, York AW, Zablocki KR, Joseph LB, Kholodovych V et al. Sugar-Based Amphiphilic Nanoparticles Arrest Atherosclerosis in Vivo. Proc Natl Acad Sci U S A. 2015; 112: 2693-2698.

[56] Lipinski MJ, Frias JC, Amirbekian V, Briley-Saebo KC, Mani V, Samber D et al. Macrophage-Specific Lipid-Based Nanoparticles Improve Cardiac Magnetic Resonance Detection and Characterization of Human Atherosclerosis. JACC Cardiovasc Imaging. 2009; 2: 637-647.

[57] Wu C, Lin J, Weng Y, Zeng DN, Xu J, Luo S et al. Myeloid Signature Reveals Immune Contexture and Predicts the Prognosis of Hepatocellular Carcinoma. J Clin Invest. 2020;

[58] Mooberry LK, Nair M, Paranjape S, McConathy WJ, Lacko AG. Receptor Mediated Uptake of Paclitaxel From a Synthetic High Density Lipoprotein Nanocarrier. J Drug Target. 2010; 18: 53-58.

[59] Zhang I, Cui $Y$, Amiri A, Ding $Y$, Campbell RE, Maysinger D et al. Pharmacological Inhibition of Lipid Droplet Formation Enhances the Effectiveness of Curcumin in Glioblastoma. Eur J Pharm Biopharm. 2016; 100: 66-76.

[60] Cotte AK, Aires V, Fredon M, Limagne E, Derangère V, Thibaudin M et al. Lysophosphatidylcholine Acyltransferase 2-Mediated Lipid Droplet 
Production Supports Colorectal Cancer Chemoresistance. Nat Commun. 2018; 9: 322.

[61] Bandyopadhyay A, Fine RL, Demento S, Bockenstedt LK, Fahmy TM. The Impact of Nanoparticle Ligand Density on Dendritic-Cell Targeted Vaccines. Biomaterials. 2011; 32: 3094-3105.

[62] Mould KJ, Jackson ND, Henson PM, Seibold M, Janssen WJ. Single Cell RNA Sequencing Identifies Unique Inflammatory Airspace Macrophage Subsets. JCI Insight. 2019; 4: e126556.

[63] Georgoudaki AM, Prokopec KE, Boura VF, Hellqvist E, Sohn S, Östling J et al. Reprogramming Tumor-Associated Macrophages By Antibody Targeting Inhibits Cancer Progression and Metastasis. Cell Rep. 2016; 15: 2000-2011.

[64] Hamilton RF, Buckingham S, Holian A. The Effect of Size on Ag Nanosphere Toxicity in Macrophage Cell Models and Lung Epithelial Cell Lines is Dependent on Particle Dissolution. Int J Mol Sci. 2014; 15: 6815-6830.

[65] Hirano S, Kanno S, Furuyama A. Multi-Walled Carbon Nanotubes Injure the Plasma Membrane of Macrophages. Toxicol Appl Pharmacol. 2008; 232: 244-251.

[66] Chao Y, Makale M, Karmali PP, Sharikov Y, Tsigelny I, Merkulov S et al. Recognition of Dextran-Superparamagnetic Iron Oxide Nanoparticle Conjugates (Feridex) Via Macrophage Scavenger Receptor Charged Domains. Bioconjug Chem. 2012; 23: 1003-1009.

[67] Kanno S, Furuyama A, Hirano S. A Murine Scavenger Receptor MARCO Recognizes Polystyrene Nanoparticles. Toxicol Sci. 2007; 97: 398-406.

[68] Gilleron J, Querbes W, Zeigerer A, Borodovsky A, Marsico G, Schubert U et al. Image-Based Analysis of Lipid Nanoparticle-Mediated siRNA Delivery, Intracellular Trafficking and Endosomal Escape. Nat Biotechnol. 2013; 31: 638-646.

[69] Saunders KO. Conceptual Approaches to Modulating Antibody Effector Functions and Circulation Half-Life. Front Immunol. 2019; 10: 1296.

[70] Czajkowsky DM, Hu J, Shao Z, Pleass RJ. Fc-Fusion Proteins: New Developments and Future Perspectives. EMBO Mol Med. 2012; 4: 1015-1028.

[71] Sarett SM, Werfel TA, Lee L, Jackson MA, Kilchrist KV, Brantley-Sieders D et al. Lipophilic Sirna Targets Albumin in Situ and Promotes Bioavailability, Tumor Penetration, and Carrier-Free Gene Silencing. Proc Natl Acad Sci U S A. 2017; 114: E6490-E6497.

[72] Tian R, Zeng Q, Zhu S, Lau J, Chandra S, et al. Albumin-chaperoned Cyanine Dye Yields Superbright NIR-II Fluorophore With Enhanced Pharmacokinetics. Sci Adv 2019; 5: eaaw0672.

[73] Kuo TT, Aveson VG. Neonatal Fc Receptor and IgG-Based Therapeutics. MAbs. 2011; 3: 422-430.

[74] Pridgen EM, Alexis F, Kuo TT, Levy-Nissenbaum E, Karnik R, Blumberg RS et al. Transepithelial Transport of Fc-Targeted Nanoparticles By the Neonatal Fc Receptor for Oral Delivery. Sci Transl Med. 2013; 5: 213ra167.

[75] Kiessling P, Lledo-Garcia R, Watanabe S, Langdon G, Tran D, Bari M et al. The FcRn Inhibitor Rozanolixizumab Reduces Human Serum IgG Concentration: A Randomized Phase 1 Study. Sci Transl Med. 2017; 9:

[76] Grevys A, Nilsen J, Sand KMK, Daba MB, Øynebråten I, Bern M et al. A Human Endothelial Cell-Based Recycling Assay for Screening of FcRn Targeted Molecules. Nat Commun. 2018; 9: 621.

[77] Gautier EL, Shay T, Miller J, Greter M, Jakubzick C, Ivanov S et al. Gene-Expression Profiles and Transcriptional Regulatory Pathways That Underlie the Identity and Diversity of Mouse Tissue Macrophages. Nat Immunol. 2012; 13: 1118-1128.

[78] Lux A, Yu X, Scanlan CN, Nimmerjahn F. Impact of Immune Complex Size and Glycosylation on IgG Binding to Human Fcyrs. J Immunol. 2013; 190: 4315-4323.

[79] Schlothauer T, Herter S, Koller CF, Grau-Richards S, Steinhart V, Spick C et al. Novel Human IgG1 and IgG4 Fc-Engineered Antibodies With Completely Abolished Immune Effector Functions. Protein Eng Des Sel. 2016; 29: 457-466.

[80] Arlauckas SP, Garris CS, Kohler RH, Kitaoka M, Cuccarese MF, Yang KS et al. In Vivo Imaging Reveals a Tumor-Associated Macrophage-Mediated Resistance Pathway in Anti-PD-1 Therapy. Sci Transl Med. 2017; 9: eaal3604.

[81] Li R, Attari A, Prytyskach M, Garlin MA, Weissleder R, Miller MA et al. Single-Cell Intravital Microscopy of Trastuzumab Quantifies Heterogeneous in Vivo Kinetics. Cytometry A. 2020; 97: 528-539.

[82] Liu PT, Stenger S, Tang DH, Modlin RL. Cutting Edge: Vitamin D-Mediated Human Antimicrobial Activity Against Mycobacterium Tuberculosis is Dependent on the Induction of Cathelicidin. J Immunol. 2007; 179: 2060-2063.

[83] Canton J, Khezri R, Glogauer M, Grinstein S. Contrasting Phagosome pH Regulation and Maturation in Human M1 and M2 Macrophages. Mol Biol Cell. 2014; 25: 3330-3341.

[84] Baker K, Rath T, Pyzik M, Blumberg RS. The Role of FcRn in Antigen Presentation. Front Immunol. 2014; 5: 408.

[85] Guerriero JL, Sotayo A, Ponichtera HE, Castrillon JA, Pourzia AL, Schad S et al. Class IIa HDAC Inhibition Reduces Breast Tumours and Metastases Through Anti-Tumour Macrophages. Nature. 2017; 543: 428-432.

[86] Pathria P, Louis TL, Varner JA. Targeting Tumor-Associated Macrophages in Cancer. Trends Immunol. 2019; 40: 310-327.

[87] te Velde AA, de Waal Malefijt R, Huijbens RJ, de Vries JE; Figdor CG. Il-10 Stimulates Monocyte Fc Gamma R Surface Expression and Cytotoxic Activity. Distinct Regulation of Antibody-Dependent Cellular Cytotoxicity By Ifn-Gamma, Il-4, and Il-10. J Immunol. 1992; 149: 4048-4052.

[88] Hilderbrand SA, Kelly KA, Niedre M; Weissleder R. Near Infrared Fluorescence-Based Bacteriophage Particles for Ratiometric pH Imaging. Bioconjug Chem. 2008; 19: 1635-1639.
[89] Huang J, Ying L, Yang X, Yang Y, Quan K, Wang H et al. Ratiometric Fluorescent Sensing of $\mathrm{pH}$ Values in Living Cells By Dual-Fluorophore-labeled I-Motif Nanoprobes. Anal Chem. 2015; 87: 8724-8731.

[90] Cochain C, Vafadarnejad E, Arampatzi P, Pelisek J, Winkels H, Ley K et al. Single-Cell RNA-Seq Reveals the Transcriptional Landscape and Heterogeneity of Aortic Macrophages in Murine Atherosclerosis. Circ Res. 2018; 122: 1661-1674.

[91] Lawrence T, Natoli G. Transcriptional Regulation of Macrophage Polarization: Enabling Diversity With Identity. Nat Rev Immunol. 2011; 11: 750-761.

[92] Jablonski KA, Amici SA, Webb LM, Ruiz-Rosado JD, Popovich PG, Partida-Sanchez $S$ et al. Novel Markers to Delineate Murine M1 and M2 Macrophages. PLoS One. 2015; 10: e0145342.

[93] Rodell CB, Arlauckas SP, Cuccarese MF, Garris CS, Li R, Ahmed MS et al. TLR7/8-Agonist-loaded Nanoparticles Promote the Polarization of Tumour-Associated Macrophages to Enhance Cancer Immunotherapy. Nat Biomed Eng. 2018; 2: 578-588.

[94] Arlauckas SP, Garren SB, Garris CS, Kohler RH, Oh J, Pittet MJ et al. Arg1 Expression Defines Immunosuppressive Subsets of Tumor-Associated Macrophages. Theranostics. 2018; 8: 5842-5854.

[95] Chen F, Wang G, Griffin JI, Brenneman B, Banda NK, Holers VM et al. Complement Proteins Bind to Nanoparticle Protein Corona and Undergo Dynamic Exchange in Vivo. Nat Nanotechnol. 2017; 12: 387-393.

[96] Kouser L, Madhukaran SP, Shastri A, Saraon A, Ferluga J, Al-Mozaini M et al. Emerging and Novel Functions of Complement Protein C1q. Front Immunol. 2015; 6: 317 .

[97] Di Gaetano N, Cittera E, Nota R, Vecchi A, Grieco V, Scanziani E et al. Complement Activation Determines the Therapeutic Activity of Rituximab in Vivo. J Immunol. 2003; 171: 1581-1587.

[98] Cartron G, Trappe RU, Solal-Céligny P, Hallek M. Interindividual Variability of Response to Rituximab: From Biological Origins to Individualized Therapies. Clin Cancer Res. 2011; 17: 19-30.

[99] Grandjean CL, Montalvao F, Celli S, Michonneau D, Breart B, Garcia Z et al. Intravital Imaging Reveals Improved Kupffer Cell-Mediated Phagocytosis as a Mode of Action of Glycoengineered Anti-CD20 Antibodies. Sci Rep. 2016; 6: 34382.

[100]Jones CF, Campbell RA, Brooks AE, Assemi S, Tadjiki S, Thiagarajan G et al. Cationic PAMAM Dendrimers Aggressively Initiate Blood Clot Formation. ACS Nano. 2012; 6: 9900-9910.

[101]Jones CF, Campbell RA, Franks Z, Gibson CC, Thiagarajan G, Vieira-de-Abreu A et al. Cationic PAMAM Dendrimers Disrupt Key Platelet Functions. Mol Pharm. 2012; 9: 1599-1611.

[102]Rodriguez PL, Harada T, Christian DA, Pantano DA, Tsai RK, Discher DE et al. Minimal "self" Peptides That Inhibit Phagocytic Clearance and Enhance Delivery of Nanoparticles. Science. 2013; 339: 971-975.

[103]Birge RB, Boeltz S, Kumar S, Carlson J, Wanderley J, Calianese D et al. Phosphatidylserine is a Global Immunosuppressive Signal in Efferocytosis, Infectious Disease, and Cancer. Cell Death Differ. 2016; 23: 962-978.

[104]Miyanishi M, Tada K, Koike M, Uchiyama Y, Kitamura T, Nagata S et al. Identification of TIM4 as a Phosphatidylserine Receptor. Nature. 2007; 450: 435-439.

[105]Nimmagadda S, Pullambhatla M, Lisok A, Hu C, Maitra A, Pomper MG. Imaging Axl Expression in Pancreatic and Prostate Cancer Xenografts. Biochem Biophys Res Commun. 2014; 443: 635-40.

[106]Cai B, Thorp EB, Doran AC, Sansbury BE, Daemen MJ, Dorweiler B et al. MERTK Receptor Cleavage Promotes Plaque Necrosis and Defective Resolution in Atherosclerosis. J Clin Invest. 2017; 127: 564-568.

[107]Miller MA, Kim E, Cuccarese MF, Plotkin AL, Prytyskach M, Kohler RH et al. Near Infrared Imaging of Mer Tyrosine Kinase (MERTK) Using MERi-SiR Reveals Tumor Associated Macrophage Uptake in Metastatic Disease. Chem Commun (Camb). 2017; 54: 42-45.

[108]Hansen CG, Nichols BJ. Molecular Mechanisms of Clathrin-Independent Endocytosis. J Cell Sci. 2009; 122: 1713-1721.

[109]Swanson JA, King JS. The Breadth of Macropinocytosis Research. Philos Trans R Soc Lond B Biol Sci. 2019; 374: 20180146.

[110]Bloomfield G, Kay RR. Uses and Abuses of Macropinocytosis. J Cell Sci. 2016; 129: 2697-2705.

[111]Lim JP, Gleeson PA. Macropinocytosis: An Endocytic Pathway for Internalising Large Gulps. Immunol Cell Biol. 2011; 89: 836-843.

[112]Mercer J, Helenius A. Virus Entry By Macropinocytosis. Nat Cell Biol. 2009; 11: 510-520.

[113]Yao W, Rose JL, Wang W, Seth S, Jiang H, Taguchi A et al. Syndecan 1 is a Critical Mediator of Macropinocytosis in Pancreatic Cancer. Nature. 2019; 568 : 410-414.

[114]Yao W, Li K, Liao K. Macropinocytosis Contributes to the Macrophage Foam Cell Formation in Raw264.7 Cells. Acta Biochim Biophys Sin (Shanghai). 2009; 41: 773-780.

[115]Domschke G, Linden F, Pawig L, Hafner A, Akhavanpoor M, Reymann J et al. Systematic RNA-Interference in Primary Human Monocyte-Derived Macrophages: A High-Throughput Platform to Study Foam Cell Formation. Sci Rep. 2018; 8: 10516.

[116]Colin M, Delporte C, Janky R, Lechon AS, Renard G, Van Antwerpen P et al. Dysregulation of Macropinocytosis Processes in Glioblastomas May be Exploited to Increase Intracellular Anti-Cancer Drug Levels: The Example of Temozolomide. Cancers (Basel). 2019; 11: 
[117]Commisso C, Davidson SM, Soydaner-Azeloglu RG, Parker SJ, Kamphorst JJ, Hackett $S$ et al. Macropinocytosis of Protein is an Amino Acid Supply Route in Ras-Transformed Cells. Nature. 2013; 497: 633-637.

[118]Norbury CC, Hewlett LJ, Prescott AR, Shastri N, Watts C. Class I Mhc Presentation of Exogenous Soluble Antigen Via Macropinocytosis in Bone Marrow Macrophages. Immunity. 1995; 3: 783-791.

[119]Carpentier JL, Lew DP, Paccaud JP, Gil R, Iacopetta B, Kazatchkine M et al. Internalization Pathway of C3b Receptors in Human Neutrophils and Its Transmodulation By Chemoattractant Receptors Stimulation. Cell Regul. 1991; 2: 41-55.

[120]Charpentier JC, Chen D, Lapinski PE, Turner J, Grigorova I, Swanson JA et al. Macropinocytosis Drives T Cell Growth By Sustaining the Activation of MTORC1. Nat Commun. 2020; 11: 180.

[121]Miao L, Lin J, Huang Y, Li L, Delcassian D, Ge Y et al. Synergistic Lipid Compositions for Albumin Receptor Mediated Delivery of Mrna to the Liver. Nat Commun. 2020; 11: 2424.

[122]Kankaanpää P, Tiitta S, Bergman L, Puranen AB, von Haartman E, Lindén M et al. Cellular Recognition and Macropinocytosis-Like Internalization of Nanoparticles Targeted to Integrin A2 $\beta 1$. Nanoscale. 2015; 7: 17889-17901.

[123]Selmi A, Vascotto F, Kautz-Neu K, Türeci Ö, Sahin U, von Stebut E et al. Uptake of Synthetic Naked RNA By Skin-Resident Dendritic Cells Via Macropinocytosis Allows Antigen Expression and Induction of T-Cell Responses in Mice. Cancer Immunol Immunother. 2016; 65: 1075-1083.

[124]Sandgren KJ, Wilkinson J, Miranda-Saksena M, McInerney GM, Byth-Wilson $\mathrm{K}$, Robinson PJ et al. A Differential Role for Macropinocytosis in Mediating Entry of the Two Forms of Vaccinia Virus Into Dendritic Cells. PLoS Pathog. 2010; 6: e1000866.

[125]Cullis J, Siolas D, Avanzi A, Barui S, Maitra A; Bar-Sagi D et al Macropinocytosis of Nab-Paclitaxel Drives Macrophage Activation in Pancreatic Cancer. Cancer Immunol Res. 2017; 5: 182-190.

[126]Redka DS, Gütschow M, Grinstein S, Canton J. Differential Ability of Proinflammatory and Anti-Inflammatory Macrophages to Perform Macropinocytosis. Molecular Biology of the Cell. 2018; 29: 53-65.

[127]Kuo MT, Chen HH, Song IS, Savaraj N; Ishikawa T. The Roles of Copper Transporters in Cisplatin Resistance. Cancer Metastasis Rev. 2007; 26: 71-83.

[128]Wu A, Grela E, Wójtowicz K, Filipczak N, Hamon Y, Luchowski R et al. Abca1 Transporter Reduces Amphotericin B Cytotoxicity in Mammalian Cells. Cell Mol Life Sci. 2019; 76: 4979-4994.

[129]Chen S, Villeneuve L, Jonker D, Couture F, Laverdière I, Cecchin E et al. ABCC5 and ABCG1 Polymorphisms Predict Irinotecan-Induced Severe Toxicity in Metastatic Colorectal Cancer Patients. Pharmacogenet Genomics. 2015; 25: 573-583.

[130]Di Martino MT, Arbitrio M, Leone E, Guzzi PH, Rotundo MS, Ciliberto D et al. Single Nucleotide Polymorphisms of ABCC5 and ABCG1 Transporter Genes Correlate to Irinotecan-Associated Gastrointestinal Toxicity in Colorectal Cancer Patients: A Dmet Microarray Profiling Study. Cancer Biol Ther. 2011; 12: 780-787.

[131]Cserepes I, Szentpétery Z, Seres L, Ozvegy-Laczka C, Langmann T, Schmitz G et al. Functional Expression and Characterization of the Human ABCG1 and ABCG4 Proteins: Indications for Heterodimerization. Biochem Biophys Res Commun. 2004; 320: 860-867.

[132]Chen M, Hu S, Li Y, Gibson AA, Fu Q, Baker SD et al. Role of OATP2B1 in Drug Absorption and Drug-Drug Interactions. Drug Metab Dispos. 2020; 48: 420-426.

[133]Nakano T, Katsuki S, Chen M, Decano JL, Halu A, Lee LH et al. Uremic Toxin Indoxyl Sulfate Promotes Proinflammatory Macrophage Activation Via the Interplay of OATP2B1 and DLL4-Notch Signaling. Circulation. 2019; 139: 78-96.

[134]Medwid S, Li MMJ, Knauer MJ, Lin K, Mansell SE, Schmerk CL et al. Fexofenadine and Rosuvastatin Pharmacokinetics in Mice With Targeted Disruption of Organic Anion Transporting Polypeptide 2b1. Drug Metab Dispos. 2019; 47: 832-842.

[135]Bhardwaj RK, Herrera-Ruiz D, Eltoukhy N, Saad M, Knipp GT. The Functional Evaluation of Human Peptide/histidine Transporter 1 (HPHT1) in Transiently Transfected Cos-7 Cells. Eur J Pharm Sci. 2006; 27: 533-542.

[136]Minhas GS, Newstead S. Structural Basis for Prodrug Recognition By the SLC15 Family of Proton-Coupled Peptide Transporters. Proc Natl Acad Sci U S A. 2019; 116: 804-809.

[137] Heinz LX, Lee J, Kapoor U, Kartnig F, Sedlyarov V, Papakostas K et al. TASL is the SLC15A4-Associated Adaptor for IRF5 Activation By TLR7-9. Nature. 2020; Epub ahead of print.

[138] Morioka S, Perry JSA, Raymond MH, Medina CB, Zhu Y, Zhao L et al. Efferocytosis Induces a Novel SLC Program to Promote Glucose Uptake and Lactate Release. Nature. 2018; 563: 714-718.

[139]Murray CM, Hutchinson R, Bantick JR, Belfield GP, Benjamin AD, Brazma D et al. Monocarboxylate Transporter MCT1 is a Target for Immunosuppression. Nat Chem Biol. 2005; 1: 371-376.

[140]Birsoy K, Wang T, Possemato R, Yilmaz OH, Koch CE, Chen WW et al. MCT1-Mediated Transport of a Toxic Molecule is an Effective Strategy for Targeting Glycolytic Tumors. Nat Genet. 2013; 45: 104-108.

[141]Vijay N, Morris ME. Role of Monocarboxylate Transporters in Drug Delivery to the Brain. Curr Pharm Des. 2014; 20: 1487-1498.

[142]Park SJ, Kim B, Choi S, Balasubramaniam S, Lee SC, Lee JY et al. Imaging Inflammation Using an Activated Macrophage Probe With SLC18B1 as the Activation-Selective Gating Target. Nat Commun. 2019; 10: 1111.
[143]Ardi VC, Kupriyanova TA, Deryugina EI, Quigley JP. Human Neutrophils Uniquely Release TIMP-Free MMP-9 to Provide a Potent Catalytic Stimulator of Angiogenesis. Proc Natl Acad Sci U S A. 2007; 104: 20262-20267.

[144]Gough PJ, Gomez IG, Wille PT, Raines EW. Macrophage Expression of Active MMP-9 Induces Acute Plaque Disruption in Apoe-Deficient Mice. J Clin Invest. 2006; 116: 59-69.

[145]Vasiljeva O, Hostetter DR, Moore SJ, Winter MB. The Multifaceted Roles of Tumor-Associated Proteases and Harnessing Their Activity for Prodrug Activation. Biol Chem. 2019; Online ahead of print.

[146]Weissleder R, Tung $\mathrm{CH}$, Mahmood U, Bogdanov A. In Vivo Imaging of Tumors With Protease-Activated Near-Infrared Fluorescent Probes. Nat Biotechnol. 1999; 17: 375-378.

[147]Anani T, Panizzi P, David AE. Nanoparticle-Based Probes to Enable Noninvasive Imaging of Proteolytic Activity for Cancer Diagnosis. Nanomedicine (Lond). 2016; 11: 2007-2022.

[148]Matusiak N, van Waarde A, Bischoff R, Oltenfreiter R, van de Wiele C, Dierckx RA et al. Probes for Non-Invasive Matrix Metalloproteinase-Targeted Imaging With PET and SPECT. Curr Pharm Des. 2013; 19: 4647-4672.

[149]Nelson ER, Wardell SE, Jasper JS, Park S, Suchindran S, Howe MK et al. 27-Hydroxycholesterol Links Hypercholesterolemia and Breast Cancer Pathophysiology. Science. 2013; 342: 1094-1098.

[150]Behmoaras J, Diaz AG, Venda L, Ko JH, Srivastava P, Montoya A et al. Macrophage Epoxygenase Determines a Profibrotic Transcriptome Signature. J Immunol. 2015; 194: 4705-4716.

[151]Di L. The Impact of Carboxylesterases in Drug Metabolism and Pharmacokinetics. Curr Drug Metab. 2019; 20: 91-102.

[152]Shi J, Wang X, Eyler RF, Liang Y, Liu L, Mueller BA et al. Association of Oseltamivir Activation With Gender and Carboxylesterase 1 Genetic Polymorphisms. Basic Clin Pharmacol Toxicol. 2016; 119: 555-561.

[153]Laizure SC, Herring V, Hu Z, Witbrodt K; Parker RB. The Role of Human Carboxylesterases in Drug Metabolism: Have We Overlooked Their Importance. Pharmacotherapy. 2013; 33: 210-222.

[154]Chen S, Zaifman J, Kulkarni JA, Zhigaltsev IV, Tam YK, Ciufolini MA et al. Dexamethasone Prodrugs as Potent Suppressors of the Immunostimulatory Effects of Lipid Nanoparticle Formulations of Nucleic Acids. J Control Release. 2018; 286: 46-54

[155]Mutch E, Nave R, McCracken N, Zech K, Williams FM. The Role of Esterases in the Metabolism of Ciclesonide to Desisobutyryl-Ciclesonide in Human Tissue. Biochem Pharmacol. 2007; 73: 1657-1664.

[156]He G, Massarella J, Ward P. Clinical Pharmacokinetics of the Prodrug Oseltamivir and Its Active Metabolite Ro 64-0802. Clin Pharmacokinet. 1999; 37: 471-484.

[157]Verbrugge SE, Al M, Assaraf YG, Kammerer S, Chandrupatla DM, Honeywell $\mathrm{R}$ et al. Multifactorial Resistance to Aminopeptidase Inhibitor Prodrug Chr2863 in Myeloid Leukemia Cells: Down-Regulation of Carboxylesterase 1, Drug Sequestration in Lipid Droplets and Pro-Survival Activation ERK/AKT/MTOR. Oncotarget. 2016; 7: 5240-5257.

[158]Biggadike K, Uings I; Farrow SN. Designing Corticosteroid Drugs for Pulmonary Selectivity. Proc Am Thorac Soc. 2004; 1: 352-355.

[159]Jones RD, Taylor AM, Tong EY, Repa JJ. Carboxylesterases Are Uniquely Expressed Among Tissues and Regulated By Nuclear Hormone Receptors in the Mouse. Drug Metab Dispos. 2013; 41: 40-49.

[160]Ubink R, Dirksen EHC, Rouwette M, Bos ES, Janssen I, Egging DF et al. Unraveling the Interaction Between Carboxylesterase $1 \mathrm{c}$ and the Antibody-Drug Conjugate SYD985: Improved Translational PK/PD By Using Ces1c Knockout Mice. Mol Cancer Ther. 2018; 17: 2389-2398.

[161]Dai Q, Wilhelm S, Ding D, Syed AM, Sindhwani S, Zhang Y et al. Quantifying the Ligand-Coated Nanoparticle Delivery to Cancer Cells in Solid Tumors. ACS Nano. 2018; 12: 8423-8435.

[162]Tavares AJ, Poon W, Zhang YN, Dai Q, Besla R, Ding D et al. Effect of Removing Kupffer Cells on Nanoparticle Tumor Delivery. Proc Natl Acad Sci US A. 2017; 114: E10871-E10880.

[163]Li F, Ulrich M, Jonas M, Stone IJ, Linares G, Zhang X et al. Tumor-Associated Macrophages Can Contribute to Antitumor Activity Through FcyR-Mediated Processing of Antibody-Drug Conjugates. Mol Cancer Ther. 2017; 16: 1347-1354

[164]De La Fuente A, Zilio S, Caroli J, Van Simaeys D, Mazza EMC, Ince TA et al. Aptamers Against Mouse and Human Tumor-Infiltrating Myeloid Cells as Reagents for Targeted Chemotherapy. Sci Transl Med. 2020; 12: eaav9760.

[165]Oh N, Kim Y, Kweon HS, Oh WY, Park JH. Macrophage-Mediated Exocytosis of Elongated Nanoparticles Improves Hepatic Excretion and Cancer Phototherapy. ACS Appl Mater Interfaces. 2018; 10: 28450-28457.

[166]Zhang F, Parayath NN, Ene CI, Stephan SB, Koehne AL, Coon ME et al. Genetic Programming of Macrophages to Perform Anti-Tumor Functions Using Targeted mRNA Nanocarriers. Nat Commun. 2019; 10: 3974.

[167]Miao L, Li L, Huang Y, Delcassian D, Chahal J, Han J et al. Delivery of mRNA Vaccines With Heterocyclic Lipids Increases Anti-Tumor Efficacy By STING-Mediated Immune Cell Activation. Nat Biotechnol. 2019; 37: 1174-1185.

[168]Atukorale PU, Raghunathan SP, Raguveer V, Moon TJ, Zheng C, et al Nanoparticle Encapsulation of Synergistic Immune Agonists Enables Systemic Codelivery to Tumor Sites and IFN $\beta$-Driven Antitumor Immunity. Cancer Res. 2019 Oct 15;79(20):5394-5406.

[169]Ng TSC, Garlin MA, Weissleder R, Miller MA. Improving Nanotherapy Delivery and Action Through Image-Guided Systems Pharmacology. Theranostics. 2020; 10: 968-997. 
[170]Miller MA, Mikula H, Luthria G, Li R, Kronister S, Prytyskach M et al. Modular Nanoparticulate Prodrug Design Enables Efficient Treatment of Solid Tumors Using Bioorthogonal Activation. ACS Nano. 2018; 12: 12814-12826.

[171]Sun X, Yan X, Jacobson O, Sun W, Wang Z, Tong X et al. Improved Tumor Uptake By Optimizing Liposome Based Res Blockade Strategy. Theranostics. 2017; 7: 319-328.

[172]Prabhakar U, Maeda H, Jain RK, Sevick-Muraca EM, Zamboni W, Farokhzad $\mathrm{OC}$ et al. Challenges and Key Considerations of the Enhanced Permeability and Retention Effect for Nanomedicine Drug Delivery in Oncology. Cancer Res. 2013; 73: 2412-2417.

[173]Harney AS, Arwert EN, Entenberg D, Wang Y, Guo P, Qian BZ et al. Real-Time Imaging Reveals Local, Transient Vascular Permeability, and Tumor Cell Intravasation Stimulated By Tie $2^{\text {hi }}$ Macrophage-Derived Vegfa. Cancer Discov. 2015; 5: 932-943.

[174]Naumenko VA, Vlasova KY, Garanina AS, Melnikov PA, Potashnikova DM, Vishnevskiy DA et al. Extravasating Neutrophils Open Vascular Barrier and Improve Liposomes Delivery to Tumors. ACS Nano. 2019; 13: 12599-12612.

[175]Pfirschke C, Engblom C, Rickelt S, Cortez-Retamozo V, Garris C, Pucci F et al. Immunogenic Chemotherapy Sensitizes Tumors to Checkpoint Blockade Therapy. Immunity. 2016; 44: 343-354.

[176] Ma L, Dichwalkar T, Chang JYH, Cossette B, Garafola D, Zhang AQ et al. Enhanced Car-T Cell Activity Against Solid Tumors By Vaccine Boosting Through the Chimeric Receptor. Science. 2019; 365: 162-168.

[177]Ponomarev V. Advancing Immune and Cell-Based Therapies Through Imaging. Mol Imaging Biol. 2017; 19(3):379-384.

[178]Fruhwirth GO, Kneilling M, de Vries IJM, Weigelin B, Srinivas M, Aarntzen EHJG. The Potential of In Vivo Imaging for Optimization of Molecular and Cellular Anti-cancer Immunotherapies. Mol Imaging Biol. 2018; 20: 696-704.

[179]Levi J, Lam T, Goth SR, Yaghoubi S, Bates J, et al. Imaging of Activated T Cells as an Early Predictor of Immune Response to Anti-PD-1 Therapy. Cancer Res. 2019; 79: 3455-3465.

[180]Pandit-Taskar N, Postow MA, Hellmann MD, Harding JJ, Barker CA, et al. First-in-Humans Imaging With ${ }^{89} \mathrm{Zr}$-Df-IAB22M2C Anti-CD8 Minibody in Patients With Solid Malignancies: Preliminary Pharmacokinetics, Biodistribution, and Lesion Targeting. J Nucl Med. 2020; 61: 512-519.

[181]Freise AC, Wu A. In Vivo Imaging With Antibodies and Engineered Fragments. Mol Immunol. 2015; 67: 142-52.

[182]Ståhl PL, Salmén F, Vickovic S, Lundmark A, Navarro JF, Magnusson J et al. Visualization and Analysis of Gene Expression in Tissue Sections By Spatial Transcriptomics. Science. 2016; 353: 78-82.

[183]Merritt CR, Ong GT, Church SE, Barker K, Danaher P, Geiss G et al. Multiplex Digital Spatial Profiling of Proteins and RNA in Fixed Tissue. Nat Biotechnol. 2020; 38: 586-599.

[184]Halpern KB, Shenhav R, Matcovitch-Natan O, Toth B, Lemze D, Golan M et al. Single-Cell Spatial Reconstruction Reveals Global Division of Labour in the Mammalian Liver. Nature. 2017; 542: 352-356.

[185]Medaglia C, Giladi A, Stoler-Barak L, De Giovanni M, Salame TM, Biram A et al. Spatial Reconstruction of Immune Niches By Combining Photoactivatable Reporters and Scrna-Seq. Science. 2017; 358: 1622-1626.

[186]Dheilly E, Battistello E, Katanayeva N, Sungalee S, Michaux J, Duns G et al. Cathepsin S Regulates Antigen Processing and $\mathrm{T}$ Cell Activity in Non-Hodgkin Lymphoma. Cancer Cell. 2020; 37: 674-689.

[187]Wu TD, Madireddi S, de Almeida PE, Banchereau R, Chen YJ, Chitre AS et al. Peripheral T Cell Expansion Predicts Tumour Infiltration and Clinical Response. Nature. 2020; 579: 274-278.

[188]Setliff I, Shiakolas AR, Pilewski KA, Murji AA, Mapengo RE, Janowska K et al. High-Throughput Mapping of B Cell Receptor Sequences to Antigen Specificity. Cell. 2019; 179: 1636-1646.

[189]Füger P, Hefendehl JK, Veeraraghavalu K, Wendeln AC, Schlosser C, Obermüller U et al. Microglia Turnover With Aging and in an Alzheimer's Model Via Long-Term in Vivo Single-Cell Imaging. Nat Neurosci. 2017; 20: 1371-1376.

[190]Weinreb C, Rodriguez-Fraticelli A, Camargo FD; Klein AM. Lineage Tracing on Transcriptional Landscapes Links State to Fate During Differentiation. Science. 2020; 367:

[191]Adamson B, Norman TM, Jost M, Cho MY, Nuñez JK, Chen Y et al. A Multiplexed Single-Cell CRISPR Screening Platform Enables Systematic Dissection of the Unfolded Protein Response. Cell. 2016; 167: 1867-1882.

[192]Denisenko E, Guo BB, Jones M, Hou R, de Kock L, Lassmann T et al. Systematic Assessment of Tissue Dissociation and Storage Biases in Single-Cell and Single-Nucleus RNA-Seq Workflows. Genome Biol. 2020; 21: 130.

[193]Philip M, Fairchild L, Sun L, Horste EL, Camara S, Shakiba M et al. Chromatin States Define Tumour-Specific T Cell Dysfunction and Reprogramming. Nature. 2017; 545: 452-456.

[194]PrabhuDas MR, Baldwin CL, Bollyky PL, Bowdish DME, Drickamer K, Febbraio $M$ et al. A Consensus Definitive Classification of Scavenger Receptors and Their Roles in Health and Disease. J Immunol. 2017; 198: 3775-3789.

[195]Uhlen M, Zhang C, Lee S, Sjöstedt E, Fagerberg L, Bidkhori G et al. A Pathology Atlas of the Human Cancer Transcriptome. Science. 2017; 357: eaan2507.

[196]Wang DD, Jin Q, Zou LW, Hou J, Lv X, Lei W et al. A Bioluminescent Sensor for Highly Selective and Sensitive Detection of Human Carboxylesterase 1 in Complex Biological Samples. Chem Commun (Camb). 2016; 52: 3183-3186.
[197]Liu ZM, Feng L, Ge GB, Lv X, Hou J, Cao YF et al. A Highly Selective Ratiometric Fluorescent Probe for in Vitro Monitoring and Cellular Imaging of Human Carboxylesterase 1. Biosens Bioelectron. 2014; 57: 30-35.

[198]Park SJ, Lee HW, Kim HR, Kang C, Kim HM. A Carboxylesterase-Selective Ratiometric Fluorescent Two-Photon Probe and Its Application to Hepatocytes and Liver Tissues. Chem Sci. 2016; 7: 3703-3709.

[199]Wang J, Williams ET, Bourgea J, Wong YN, Patten CJ. Characterization of Recombinant Human Carboxylesterases: Fluorescein Diacetate as a Probe Substrate for Human Carboxylesterase 2. Drug Metab Dispos. 2011; 39: 1329-1333.

[200]Haney MS, Bohlen CJ, Morgens DW, Ousey JA, Barkal AA, Tsui CK et al. Identification of Phagocytosis Regulators Using Magnetic Genome-Wide CRISPR Screens. Nat Genet. 2018; 50: 1716-1727.

[201]Malesci A, Bianchi P, Celesti G, Basso G, Marchesi F, Grizzi F et al. Tumor-associated macrophages and response to 5-fluorouracil adjuvant therapy in stage III colorectal cancer. Oncoimmunology 2017; 6: e1342918.

[202]Donadon M, Torzilli G, Cortese N, Soldani C, Di Tommaso L, Franceschini B et al. Macrophage morphology correlates with single-cell diversity and prognosis in colorectal liver metastasis. J Exp Med. 2020; 217: e20191847.

[203] Cassetta L, Fragkogianni S, Sims AH, Swierczak A, Forrester LM, Zhang H et al. Human Tumor-Associated Macrophage and Monocyte Transcriptional Landscapes Reveal Cancer-Specific Reprogramming, Biomarkers, and Therapeutic Targets. Cancer Cell 2019; 35: 588-602. 